\title{
4. Comercio exterior por comunidades autónomas y provincias
}


4.1. COMERCIO EXTERIOR POR COMUNIDADES AUTÓNOMAS Y PROVINCIAS

(Millones de euros)

\begin{tabular}{|c|c|c|c|c|c|c|c|c|c|c|}
\hline & \multicolumn{5}{|c|}{ Exportaciones } & \multicolumn{5}{|c|}{ Importaciones } \\
\hline & 2013 & 2014 & 2015 & 2016 & $2017^{*}$ & 2013 & 2014 & 2015 & 2016 & $2017^{*}$ \\
\hline TOTAL GENERAL ............... & $235.814,1$ & $240.581,8$ & $249.794,4$ & $256.393,4$ & $277.125,7$ & $252.346,8$ & $265.556,6$ & $274.772,3$ & $273.778,6$ & $301.870,1$ \\
\hline 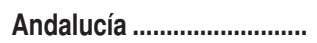 & $26.124,6$ & $26.649,6$ & $24.930,5$ & $26.823,2$ & $30.913,3$ & $30.625,8$ & $30.957,9$ & $26.534,4$ & $24.282,0$ & $29.196,6$ \\
\hline 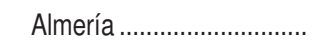 & $2.702,6$ & $2.726,6$ & $3.125,8$ & $3.378,2$ & $3.617,3$ & $2.158,8$ & $2.299,2$ & $2.322,4$ & $1.953,3$ & $2.115,4$ \\
\hline 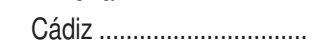 & $8.315,2$ & $7.510,0$ & $6.075,8$ & $5.658,8$ & $6.214,9$ & $13.020,0$ & $12.859,1$ & $9.199,9$ & $7.516,1$ & $9.232,6$ \\
\hline 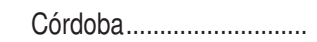 & $1.799,6$ & $1.982,9$ & $2.072,5$ & $2.178,6$ & $2.448,8$ & 684,3 & 643,2 & 852,7 & 783,2 & 893,3 \\
\hline Granada & 924,3 & 925,2 & $1.030,2$ & $1.083,9$ & $1.195,0$ & 551,8 & 648,5 & 713,8 & 695,2 & 728,2 \\
\hline Huelva .............................. & $5.685,7$ & $5.877,6$ & $4.607,7$ & $4.408,4$ & $6.384,1$ & $9.085,6$ & $8.932,5$ & $6.731,0$ & $6.241,1$ & $7.990,6$ \\
\hline Jaén........ & 729,1 & 970,1 & 946,6 & $1.178,8$ & $1.265,3$ & 498,0 & 548,4 & 696,1 & 766,3 & 878,4 \\
\hline 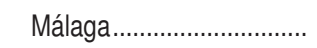 & $1.382,3$ & $1.642,5$ & $1.806,6$ & $1.995,8$ & $2.198,2$ & $1.227,4$ & $1.509,3$ & $1.740,5$ & $2.021,7$ & $3.195,9$ \\
\hline Sevilla …………………......... & $4.585,8$ & $5.014,7$ & $5.265,3$ & $6.940,7$ & $7.589,8$ & $3.399,9$ & $3.517,7$ & $4.278,1$ & $4.305,2$ & $4.162,2$ \\
\hline 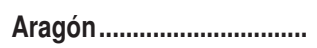 & $8.866,9$ & $9.382,4$ & $10.571,0$ & $10.895,1$ & $12.019,8$ & $6.965,7$ & $8.552,9$ & $10.270,7$ & $10.407,4$ & $10.874,8$ \\
\hline Huesca ................................. & 981,1 & 867,9 & 897,4 & 897,6 & 972,6 & 494,3 & 472,0 & 525,6 & 510,5 & 567,9 \\
\hline 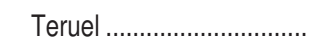 & 218,4 & 231,2 & 406,1 & 269,3 & 329,8 & 185,4 & 206,3 & 340,0 & 209,0 & 291,0 \\
\hline Zaragoza ............................... & $7.667,5$ & $8.283,2$ & $9.267,6$ & $9.728,2$ & $10.717,5$ & $6.285,9$ & $7.874,6$ & $9.405,1$ & $9.687,9$ & $10.015,9$ \\
\hline Asturias, Principado de .... & $3.843,6$ & $3.838,4$ & $3.791,0$ & $3.510,7$ & $4.175,6$ & $3.440,6$ & $3.342,0$ & $3.226,1$ & $3.087,6$ & $4.145,0$ \\
\hline Balears, Illes........................ & 834,0 & 924,0 & $1.157,2$ & $1.167,2$ & $1.853,6$ & $1.383,5$ & $1.455,0$ & $1.569,0$ & $1.417,4$ & $1.775,5$ \\
\hline 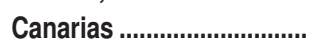 & $2.619,3$ & $2.392,5$ & $2.452,6$ & $2.061,8$ & $2.533,5$ & $4.362,9$ & $3.556,0$ & $2.991,5$ & $3.391,9$ & $4.301,0$ \\
\hline 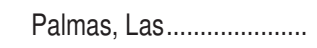 & $1.823,9$ & $1.751,8$ & $1.994,1$ & $1.613,0$ & $1.931,9$ & $1.780,9$ & $1.923,3$ & $1.821,3$ & $2.064,5$ & $2.396,4$ \\
\hline Santa Cruz de Tenerife ... & 795,3 & 640,7 & 458,5 & 448,9 & 601,7 & $2.582,0$ & $1.632,7$ & $1.170,3$ & $1.327,5$ & $1.904,6$ \\
\hline 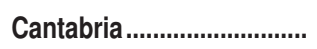 & $2.457,5$ & $2.546,5$ & $2.342,1$ & $2.345,2$ & $2.319,2$ & $1.742,8$ & $1.861,3$ & $1.980,2$ & $1.793,7$ & $1.951,8$ \\
\hline Castilla y León .................... & $12.271,0$ & $12.751,9$ & $14.881,5$ & $16.329,2$ & $15.597,6$ & $10.770,2$ & $12.244,0$ & $12.478,1$ & $12.703,6$ & $13.397,6$ \\
\hline 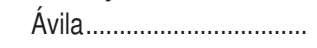 & 115,6 & 97,8 & 164,6 & 180,9 & 141,9 & 88,2 & 124,7 & 131,7 & 123,4 & 166,2 \\
\hline Burgos .................................. & $3.138,5$ & $3.009,9$ & $3.604,7$ & $3.519,8$ & $3.107,8$ & $2.331,9$ & $2.069,6$ & $2.398,2$ & $2.515,3$ & $2.522,0$ \\
\hline León.......................................... & $1.188,4$ & $1.242,2$ & $1.498,3$ & $1.429,1$ & $1.428,5$ & 371,5 & 403,4 & 431,4 & 605,3 & 894,5 \\
\hline 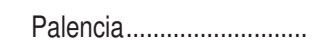 & $1.636,7$ & $1.406,8$ & $2.311,3$ & $3.819,0$ & $3.472,8$ & 332,3 & 298,0 & 348,9 & 423,2 & 500,5 \\
\hline Salamanca............................ & 882,6 & 783,5 & 918,8 & 715,6 & 675,2 & 548,9 & 586,5 & 688,5 & 599,3 & 592,8 \\
\hline Segovia.................................. & 256,1 & 287,7 & 300,5 & 311,4 & 320,9 & 166,0 & 167,8 & 187,8 & 205,8 & 201,3 \\
\hline Soria & 271,8 & 325,1 & 402,1 & 396,5 & 451,3 & 205,0 & 233,2 & 294,7 & 355,8 & 369,6 \\
\hline Valladolid .............................. & $4.619,1$ & $5.449,0$ & $5.508,8$ & $5.761,8$ & $5.797,6$ & $6.613,8$ & $8.267,2$ & $7.913,0$ & $7.783,5$ & $8.039,6$ \\
\hline Zamora ................................. & 162,2 & 149,8 & 172,3 & 195,1 & 201,5 & 112,6 & 93,7 & 84,0 & 92,0 & 111,2 \\
\hline Castilla-La Mancha ............. & $4.866,3$ & $5.398,9$ & $6.013,5$ & $6.426,2$ & $7.056,1$ & $5.717,3$ & $5.974,2$ & $6.633,8$ & $7.467,9$ & $8.432,2$ \\
\hline Albacete................................ & 814,0 & 764,9 & 849,4 & 902,9 & 969,2 & 651,5 & 629,5 & 586,6 & 624,6 & 736,7 \\
\hline Ciudad Real........................ & $1.703,2$ & $1.815,5$ & $1.809,3$ & $1.760,6$ & $2.072,6$ & 350,0 & 374,1 & 511,2 & 496,3 & 565,4 \\
\hline Cuenca & 327,3 & 333,7 & 400,3 & 471,2 & 513,9 & 89,1 & 94,2 & 107,3 & 132,6 & 189,1 \\
\hline Guadalajara ......................... & 975,9 & $1.227,5$ & $1.550,6$ & $1.753,4$ & $1.808,1$ & $2.652,0$ & $2.820,6$ & $3.551,8$ & $4.081,7$ & $4.710,0$ \\
\hline Toledo.................................. & $1.045,9$ & $1.257,3$ & $1.403,8$ & $1.538,1$ & $1.692,1$ & $1.974,6$ & $2.055,9$ & $1.876,8$ & $2.132,8$ & $2.231,0$ \\
\hline Cataluña & $58.957,2$ & $60.291,2$ & $63.885,2$ & $65.142,1$ & $70.828,7$ & $67.380,8$ & $72.220,5$ & $76.177,8$ & $77.627,1$ & $84.321,7$ \\
\hline Barcelona .............................. & $45.828,8$ & $47.184,1$ & $50.166,5$ & $51.189,5$ & $54.771,6$ & $52.943,5$ & $57.737,6$ & $62.673,8$ & $64.252,3$ & $68.232,9$ \\
\hline Girona................................... & $4.272,7$ & $4.344,7$ & $4.639,6$ & $4.728,9$ & $5.301,2$ & $2.041,6$ & $2.132,7$ & $2.301,7$ & $2.352,4$ & $2.597,2$ \\
\hline Lleida .......................................... & $1.733,5$ & $1.700,6$ & $1.869,3$ & $1.954,4$ & $2.076,3$ & 831,6 & 812,2 & 907,7 & 888,5 & 877,5 \\
\hline Tarragona.............................. & $7.122,2$ & $7.061,8$ & $7.209,7$ & $7.269,3$ & $8.679,6$ & $11.564,2$ & $11.537,9$ & $10.294,6$ & $10.134,0$ & $12.614,1$ \\
\hline Comunitat Valenciana...... & $23.608,8$ & $25.001,1$ & $28.219,6$ & $28.665,5$ & $29.371,0$ & $20.837,6$ & $21.372,9$ & $23.682,6$ & $23.884,7$ & $26.027,7$ \\
\hline Alicante/Alacant.................. & $4.530,9$ & $4.851,4$ & $4.968,4$ & $5.005,5$ & $5.125,2$ & $3.044,5$ & $3.460,1$ & $3.877,1$ & $4.038,2$ & $4.181,4$ \\
\hline Castellón/Castelló.............. & $5.656,1$ & $5.908,9$ & $6.286,3$ & $6.478,8$ & $6.864,1$ & $4.715,0$ & $4.432,2$ & $3.794,2$ & $3.617,6$ & $4.299,1$ \\
\hline Valencia/València .............. & $13.421,9$ & $14.240,7$ & $16.965,0$ & $17.181,2$ & $17.381,7$ & $13.078,0$ & $13.480,7$ & $16.011,3$ & $16.228,9$ & $17.547,2$ \\
\hline 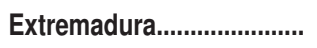 & $1.667,6$ & $1.673,7$ & $1.720,4$ & $1.689,2$ & $1.919,0$ & $1.123,2$ & 980,4 & $1.055,7$ & $1.077,2$ & $1.205,6$ \\
\hline 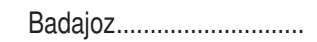 & $1.253,4$ & $1.261,9$ & $1.306,7$ & $1.284,2$ & $1.450,2$ & 786,3 & 666,6 & 676,4 & 722,5 & 826,8 \\
\hline 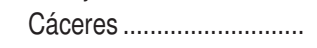 & 414,2 & 411,8 & 413,7 & 405,1 & 468,8 & 336,9 & 313,8 & 379,3 & 354,7 & 378,8 \\
\hline Galicia.............................. & $18.758,2$ & $17.809,7$ & $18.924,0$ & $19.981,3$ & $21.676,3$ & $14.639,5$ & $14.413,3$ & $15.108,5$ & $15.508,5$ & $17.140,8$ \\
\hline Coruña, A & $8.495,5$ & $7.682,2$ & $8.291,1$ & $9.403,8$ & $11.009,6$ & $7.655,8$ & $6.775,7$ & $6.240,1$ & $6.030,9$ & $6.897,9$ \\
\hline 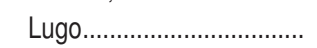 & $1.087,1$ & 966,3 & $1.174,4$ & 678,2 & 679,6 & $1.078,4$ & 829,5 & 856,4 & 622,9 & 625,8 \\
\hline 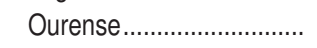 & 741,4 & 826,7 & 787,7 & 787,5 & 815,6 & 390,4 & 416,7 & 455,4 & 497,2 & 554,4 \\
\hline Pontevedra ........................... & $8.434,1$ & $8.334,5$ & $8.670,9$ & $9.111,7$ & $9.171,5$ & $5.514,9$ & $6.391,4$ & $7.556,6$ & $8.357,5$ & $9.062,7$ \\
\hline
\end{tabular}


4.1. COMERCIO EXTERIOR POR COMUNIDADES AUTÓNOMAS Y PROVINCIAS (continuación) (Millones de euros)

\begin{tabular}{|c|c|c|c|c|c|c|c|c|c|c|}
\hline & \multicolumn{5}{|c|}{ Exportaciones } & \multicolumn{5}{|c|}{ Importaciones } \\
\hline & 2013 & 2014 & 2015 & 2016 & $2017^{*}$ & 2013 & 2014 & 2015 & 2016 & $2017^{*}$ \\
\hline Madrid, Comunidad de.... & $30.771,4$ & $27.731,4$ & $27.775,8$ & $28.759,7$ & $30.510,3$ & $47.579,3$ & $50.863,6$ & $57.720,0$ & $58.363,0$ & $60.884,6$ \\
\hline Murcia, Región de............. & $9.353,0$ & $10.440,7$ & $9.379,2$ & $9.026,2$ & $10.456,7$ & $11.912,4$ & $11.959,8$ & $8.965,1$ & $8.024,8$ & $9.667,6$ \\
\hline Navarra, Com. Foral de... & $7.447,2$ & $8.141,1$ & $8.539,7$ & $8.437,2$ & $8.073,7$ & $3.916,6$ & $4.162,7$ & $4.578,2$ & $4.542,3$ & $4.432,8$ \\
\hline 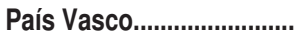 & $20.631,3$ & $22.501,0$ & $21.865,5$ & $21.615,4$ & $23.860,4$ & $15.951,8$ & $17.131,4$ & $16.818,8$ & $15.583,4$ & $18.640,8$ \\
\hline Araba/Álava ......................... & $5.302,0$ & $5.661,2$ & $5.824,8$ & $6.713,0$ & $7.136,0$ & $2.435,6$ & $2.531,0$ & $3.308,4$ & $3.725,5$ & $4.056,1$ \\
\hline Bizkaia ................................. & $8.721,1$ & $9.832,8$ & $9.053,1$ & $8.089,6$ & $9.545,4$ & $10.419,1$ & $11.322,0$ & $9.899,5$ & $8.485,3$ & $10.846,8$ \\
\hline Gipuzkoa .............................. & $6.608,2$ & $7.007,1$ & $6.987,7$ & $6.812,9$ & $7.179,0$ & $3.097,0$ & $3.278,5$ & $3.610,9$ & $3.372,5$ & $3.737,9$ \\
\hline Rioja, La............................. & $1.510,8$ & $1.644,4$ & $1.700,0$ & $1.704,4$ & $1.848,2$ & $1.067,1$ & $1.154,4$ & $1.213,0$ & $1.245,6$ & $1.361,2$ \\
\hline 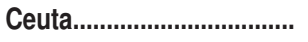 & 3,1 & 7,9 & 6,9 & 3,1 & 20,8 & 399,3 & 380,0 & 320,2 & 314,5 & 305,1 \\
\hline Melilla................................... & 34,2 & 30,0 & 43,0 & 48,3 & 49,7 & 248,3 & 262,1 & 281,4 & 292,2 & 238,1 \\
\hline No determinado ................ & $1.188,2$ & $1.425,4$ & $1.595,8$ & $1.762,4$ & $2.042,4$ & $2.282,2$ & $2.711,9$ & $3.167,3$ & $2.763,7$ & $3.569,4$ \\
\hline
\end{tabular}

*Datos provisionales.

Fuente: Subdirección General de Estudios y Evaluación de Instrumentos de Política Comercial de la Secretaría de Estado de Comercio, con datos del Departamento de Aduanas e IIEE de la Agencia Tributaria. 
4.2. ANDALUCÍA. COMERCIO EXTERIOR EN 2017

(Millones de euros)

\begin{tabular}{|c|c|c|c|c|c|c|c|c|}
\hline \multirow[b]{2}{*}{ Sectores } & \multicolumn{4}{|c|}{ Exportaciones } & \multicolumn{4}{|c|}{ Importaciones } \\
\hline & Valor & $\begin{array}{l}\% \text { de } \\
\text { la CA }\end{array}$ & $\begin{array}{l}\% \text { de } \\
\text { España }\end{array}$ & $\begin{array}{c}\text { Crecim. } \\
17 / 16\end{array}$ & Valor & $\begin{array}{l}\% \text { de } \\
\text { la CA }\end{array}$ & $\begin{array}{l}\% \text { de } \\
\text { España }\end{array}$ & $\begin{array}{c}\text { Crecim. } \\
17 / 16\end{array}$ \\
\hline TOTAL GENERAL & $30.913,3$ & 100,0 & 11,2 & 20,5 & $29.196,6$ & 100,0 & 9,7 & 20,6 \\
\hline Alimentación, bebidas y tabaco & $10.787,0$ & 34,9 & 23,6 & 9,1 & $4.157,2$ & 14,2 & 12,0 & 15,4 \\
\hline 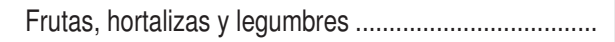 & $5.916,4$ & 19,1 & 34,3 & 4,9 & 832,0 & 2,8 & 15,7 & 18,0 \\
\hline 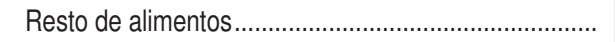 & $4.870,6$ & 15,8 & 17,1 & 14,7 & $3.325,2$ & 11,4 & 11,3 & 14,8 \\
\hline 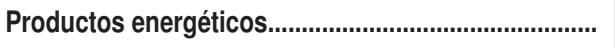 & $4.051,2$ & 13,1 & 20,7 & 27,5 & $12.624,0$ & 43,2 & 31,3 & 27,2 \\
\hline 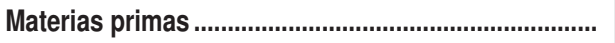 & $2.591,9$ & 8,4 & 36,3 & 43,5 & $2.765,4$ & 9,5 & 25,6 & 16,2 \\
\hline 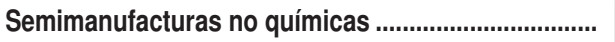 & $3.536,7$ & 11,4 & 12,6 & 12,0 & $1.359,1$ & 4,7 & 6,3 & 19,3 \\
\hline Hierro y acero & $1.218,6$ & 3,9 & 15,6 & 15,6 & 580,3 & 2,0 & 7,1 & 27,9 \\
\hline Resto de semimanufacturas no químicas ....................... & $2.318,1$ & 7,5 & 11,4 & 10,3 & 778,8 & 2,7 & 5,8 & 13,6 \\
\hline Productos químicos & $1.764,4$ & 5,7 & 4,5 & 35,0 & $2.165,2$ & 7,4 & 4,8 & 16,9 \\
\hline 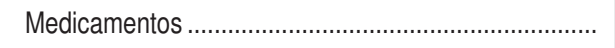 & 40,5 & 0,1 & 0,4 & $-29,9$ & 81,8 & 0,3 & 0,6 & $-27,4$ \\
\hline 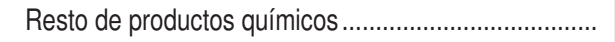 & $1.723,9$ & 5,6 & 6,1 & 38,0 & $2.083,4$ & 7,1 & 6,5 & 19,8 \\
\hline Bienes de equipo & $5.933,3$ & 19,2 & 10,5 & 53,2 & $4.341,1$ & 14,9 & 6,7 & 18,0 \\
\hline Maquinaria para la industria & 450,4 & 1,5 & 3,2 & 9,8 & 597,2 & 2,0 & 3,6 & 6,9 \\
\hline 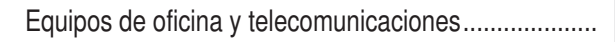 & 209,7 & 0,7 & 6,8 & 4,4 & 388,6 & 1,3 & 3,1 & 2,2 \\
\hline 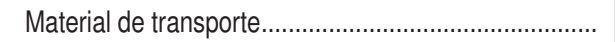 & $3.361,8$ & 10,9 & 22,2 & 121,5 & $1.867,7$ & 6,4 & 19,4 & 55,6 \\
\hline Resto de bienes de equipo & $1.911,4$ & 6,2 & 8,0 & 9,6 & $1.487,5$ & 5,1 & 5,7 & $-3,3$ \\
\hline 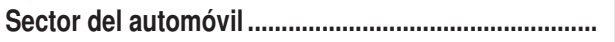 & 271,7 & 0,9 & 0,6 & 6,5 & 211,2 & 0,7 & 0,5 & 37,6 \\
\hline Automóviles y motos & 54,1 & 0,2 & 0,2 & $-7,4$ & 101,6 & 0,3 & 0,5 & 7,2 \\
\hline 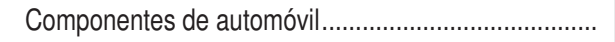 & 217,6 & 0,7 & 1,7 & 10,6 & 109,7 & 0,4 & 0,6 & 86,5 \\
\hline 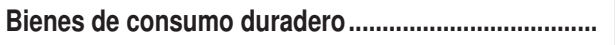 & 332,3 & 1,1 & 7,4 & $-6,7$ & 293,8 & 1,0 & 3,7 & 18,2 \\
\hline Manufacturas de consumo & 774,4 & 2,5 & 2,7 & 1,2 & $1.260,6$ & 4,3 & 3,4 & 7,0 \\
\hline 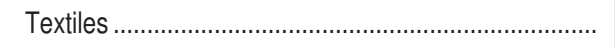 & 440,2 & 1,4 & 2,6 & 1,6 & 733,5 & 2,5 & 3,5 & 7,3 \\
\hline 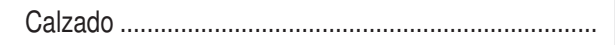 & 33,3 & 0,1 & 1,2 & 6,2 & 122,6 & 0,4 & 3,9 & 17,5 \\
\hline Resto de manufacturas de consumo & 300,9 & 1,0 & 3,6 & 0,0 & 404,6 & 1,4 & 3,3 & 3,7 \\
\hline Otras mercancías & 870,4 & 2,8 & 24,8 & $-18,2$ & 18,9 & 0,1 & 1,7 & $-59,8$ \\
\hline
\end{tabular}


4.3. ARAGÓN. COMERCIO EXTERIOR EN 2017

(Millones de euros)

\begin{tabular}{|c|c|c|c|c|c|c|c|c|}
\hline \multirow[b]{2}{*}{ Sectores } & \multicolumn{4}{|c|}{ Exportaciones } & \multicolumn{4}{|c|}{ Importaciones } \\
\hline & Valor & $\begin{array}{l}\% \text { de } \\
\text { la CA }\end{array}$ & $\begin{array}{l}\% \text { de } \\
\text { España }\end{array}$ & $\begin{array}{c}\text { Crecim. } \\
17 / 16\end{array}$ & Valor & $\begin{array}{l}\% \text { de } \\
\text { la CA }\end{array}$ & $\begin{array}{l}\% \text { de } \\
\text { España }\end{array}$ & $\begin{array}{c}\text { Crecim. } \\
17 / 16\end{array}$ \\
\hline TOTAL GENERAL & $12.019,8$ & 100,0 & 4,3 & 10,6 & $10.874,8$ & 100,0 & 3,6 & 4,6 \\
\hline Alimentación, bebidas y tabaco & $1.495,0$ & 12,4 & 3,3 & 13,9 & 637,1 & 5,9 & 1,8 & $-1,1$ \\
\hline 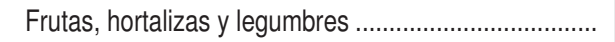 & 235,9 & 2,0 & 1,4 & 2,2 & 37,5 & 0,3 & 0,7 & 3,5 \\
\hline Resto de alimentos & $1.259,2$ & 10,5 & 4,4 & 16,4 & 599,6 & 5,5 & 2,0 & $-1,4$ \\
\hline 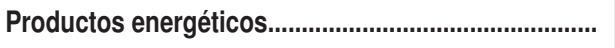 & 45,0 & 0,4 & 0,2 & 48,3 & 77,2 & 0,7 & 0,2 & 108,5 \\
\hline 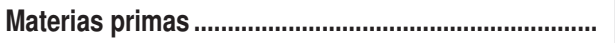 & 100,8 & 0,8 & 1,4 & 37,4 & 316,9 & 2,9 & 2,9 & 14,4 \\
\hline 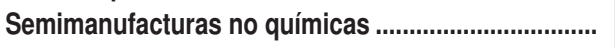 & 778,7 & 6,5 & 2,8 & 10,0 & 487,8 & 4,5 & 2,3 & 8,1 \\
\hline Hierro y acero & 189,9 & 1,6 & 2,4 & 7,5 & 163,8 & 1,5 & 2,0 & 21,2 \\
\hline Resto de semimanufacturas no químicas ....................... & 588,8 & 4,9 & 2,9 & 10,8 & 324,1 & 3,0 & 2,4 & 2,5 \\
\hline Productos químicos & 811,5 & 6,8 & 2,1 & 5,6 & 899,6 & 8,3 & 2,0 & 15,3 \\
\hline 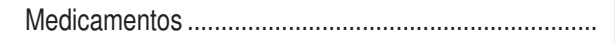 & 105,1 & 0,9 & 1,0 & 9,3 & 40,7 & 0,4 & 0,3 & $-31,3$ \\
\hline 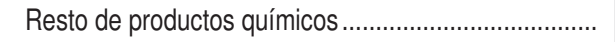 & 706,4 & 5,9 & 2,5 & 5,1 & 859,0 & 7,9 & 2,7 & 19,1 \\
\hline Bienes de equipo & $1.974,2$ & 16,4 & 3,5 & 9,6 & $2.746,7$ & 25,3 & 4,2 & 0,9 \\
\hline Maquinaria para la industria & 855,8 & 7,1 & 6,0 & 4,4 & 850,6 & 7,8 & 5,1 & 5,6 \\
\hline 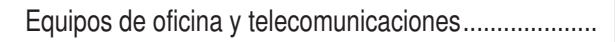 & 82,8 & 0,7 & 2,7 & $-11,1$ & 375,9 & 3,5 & 3,0 & $-26,0$ \\
\hline 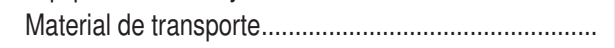 & 234,2 & 1,9 & 1,5 & 14,8 & 247,6 & 2,3 & 2,6 & 11,8 \\
\hline Resto de bienes de equipo & 801,4 & 6,7 & 3,4 & 17,2 & $1.272,6$ & 11,7 & 4,9 & 7,1 \\
\hline 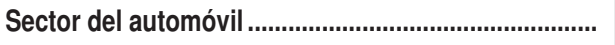 & $3.890,4$ & 32,4 & 8,6 & 13,0 & $1.899,6$ & 17,5 & 4,9 & 7,0 \\
\hline Automóviles y motos & $3.443,9$ & 28,7 & 10,7 & 13,6 & 745,6 & 6,9 & 3,9 & 17,4 \\
\hline 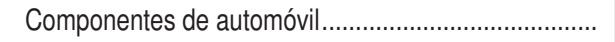 & 446,5 & 3,7 & 3,4 & 8,1 & $1.154,0$ & 10,6 & 5,8 & 1,2 \\
\hline 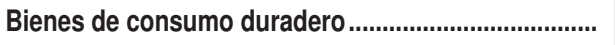 & 820,8 & 6,8 & 18,3 & $-4,5$ & 693,1 & 6,4 & 8,6 & $-1,8$ \\
\hline Manufacturas de consumo & $2.088,6$ & 17,4 & 7,4 & 13,5 & $3.106,1$ & 28,6 & 8,5 & 4,1 \\
\hline 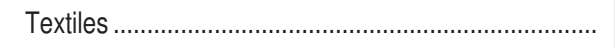 & $1.622,3$ & 13,5 & 9,6 & 16,5 & $2.524,7$ & 23,2 & 11,9 & 11,8 \\
\hline 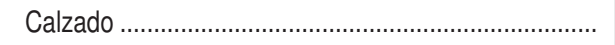 & 112,2 & 0,9 & 4,0 & $-3,7$ & 220,9 & 2,0 & 7,1 & $-7,8$ \\
\hline Resto de manufacturas de consumo & 354,1 & 2,9 & 4,2 & 6,8 & 360,6 & 3,3 & 3,0 & $-25,7$ \\
\hline Otras mercancías & 14,9 & 0,1 & 0,4 & $-46,8$ & 10,7 & 0,1 & 1,0 & $-35,2$ \\
\hline
\end{tabular}


4.4. ASTURIAS, PRINCIPADO DE. COMERCIO EXTERIOR EN 2017

(Millones de euros)

\begin{tabular}{|c|c|c|c|c|c|c|c|c|}
\hline \multirow[b]{2}{*}{ Sectores } & \multicolumn{4}{|c|}{ Exportaciones } & \multicolumn{4}{|c|}{ Importaciones } \\
\hline & Valor & $\begin{array}{l}\% \text { de } \\
\text { la CA }\end{array}$ & $\begin{array}{c}\% \text { de } \\
\text { España }\end{array}$ & $\begin{array}{c}\text { Crecim. } \\
17 / 16\end{array}$ & Valor & $\begin{array}{l}\% \text { de } \\
\text { la CA }\end{array}$ & $\begin{array}{l}\% \text { de } \\
\text { España }\end{array}$ & $\begin{array}{c}\text { Crecim. } \\
17 / 16\end{array}$ \\
\hline TOTAL GENERAL & $4.175,6$ & 100,0 & 1,5 & 19,4 & $4.145,0$ & 100,0 & 1,4 & 32,1 \\
\hline Alimentación, bebidas y tabaco & 247,4 & 5,9 & 0,5 & 64,7 & 250,2 & 6,0 & 0,7 & 9,6 \\
\hline 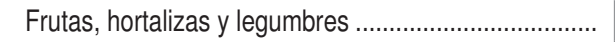 & 6,9 & 0,2 & 0,0 & 115,7 & 31,2 & 0,8 & 0,6 & 1,9 \\
\hline 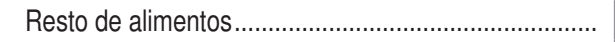 & 240,5 & 5,8 & 0,8 & 63,6 & 218,9 & 5,3 & 0,7 & 10,8 \\
\hline 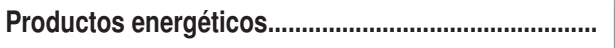 & 112,1 & 2,7 & 0,6 & 57,0 & $1.000,3$ & 24,1 & 2,5 & 82,1 \\
\hline 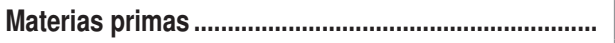 & 421,0 & 10,1 & 5,9 & 29,9 & $1.459,5$ & 35,2 & 13,5 & 44,2 \\
\hline 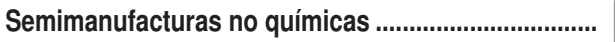 & $1.772,3$ & 42,4 & 6,3 & 15,8 & 532,2 & 12,8 & 2,5 & 11,5 \\
\hline Hierro y acero & 459,6 & 11,0 & 5,9 & $-25,4$ & 282,1 & 6,8 & 3,5 & $-5,2$ \\
\hline Resto de semimanufacturas no químicas ....................... & $1.312,7$ & 31,4 & 6,5 & 43,6 & 250,1 & 6,0 & 1,9 & 39,2 \\
\hline Productos químicos & 300,5 & 7,2 & 0,8 & $-1,2$ & 308,1 & 7,4 & 0,7 & 3,4 \\
\hline 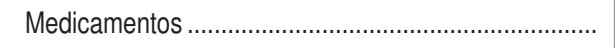 & 27,3 & 0,7 & 0,3 & 4,9 & 22,6 & 0,5 & 0,2 & $-26,6$ \\
\hline 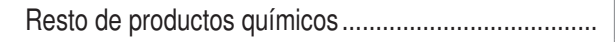 & 273,2 & 6,5 & 1,0 & $-1,7$ & 285,5 & 6,9 & 0,9 & 6,8 \\
\hline 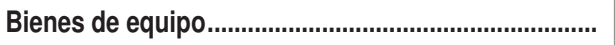 & 933,1 & 22,3 & 1,7 & 20,4 & 346,8 & 8,4 & 0,5 & $-0,5$ \\
\hline Maquinaria para la industria & 357,6 & 8,6 & 2,5 & 17,1 & 130,5 & 3,1 & 0,8 & $-8,9$ \\
\hline Equipos de oficina y telecomunicaciones......................... & 8,7 & 0,2 & 0,3 & 33,8 & 29,5 & 0,7 & 0,2 & 41,4 \\
\hline 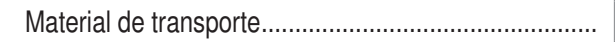 & 150,3 & 3,6 & 1,0 & 21,2 & 19,7 & 0,5 & 0,2 & $-1,2$ \\
\hline Resto de bienes de equipo & 416,5 & 10,0 & 1,7 & 22,9 & 167,0 & 4,0 & 0,6 & 1,6 \\
\hline 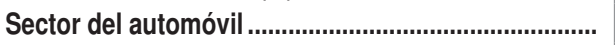 & 92,4 & 2,2 & 0,2 & 21,6 & 44,2 & 1,1 & 0,1 & $-13,2$ \\
\hline Automóviles y motos & 16,6 & 0,4 & 0,1 & 30,4 & 29,4 & 0,7 & 0,2 & 12,4 \\
\hline 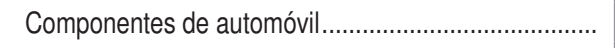 & 75,7 & 1,8 & 0,6 & 19,9 & 14,8 & 0,4 & 0,1 & $-40,2$ \\
\hline 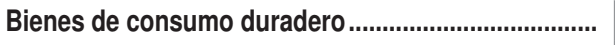 & 38,6 & 0,9 & 0,9 & 7,5 & 16,0 & 0,4 & 0,2 & $-17,5$ \\
\hline Manufacturas de consumo & 159,0 & 3,8 & 0,6 & 157,9 & 128,4 & 3,1 & 0,4 & 10,3 \\
\hline 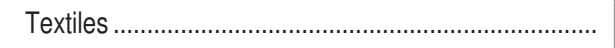 & 114,1 & 2,7 & 0,7 & 377,2 & 49,0 & 1,2 & 0,2 & 11,8 \\
\hline Calzado & 1,1 & 0,0 & 0,0 & $-42,7$ & 4,9 & 0,1 & 0,2 & $-28,5$ \\
\hline Resto de manufacturas de consumo & 43,8 & 1,0 & 0,5 & 22,4 & 74,5 & 1,8 & 0,6 & 13,4 \\
\hline Otras mercancías & 99,4 & 2,4 & 2,8 & $-41,3$ & 59,2 & 1,4 & 5,4 & 53,9 \\
\hline
\end{tabular}


4.5. BALEARS, ILLES. COMERCIO EXTERIOR EN 2017

(Millones de euros)

\begin{tabular}{|c|c|c|c|c|c|c|c|c|}
\hline \multirow[b]{2}{*}{ Sectores } & \multicolumn{4}{|c|}{ Exportaciones } & \multicolumn{4}{|c|}{ Importaciones } \\
\hline & Valor & $\begin{array}{l}\% \text { de } \\
\text { la CA }\end{array}$ & $\begin{array}{l}\% \text { de } \\
\text { España }\end{array}$ & $\begin{array}{c}\text { Crecim. } \\
17 / 16\end{array}$ & Valor & $\begin{array}{l}\% \text { de } \\
\text { la CA }\end{array}$ & $\begin{array}{l}\% \text { de } \\
\text { España }\end{array}$ & $\begin{array}{c}\text { Crecim. } \\
17 / 16\end{array}$ \\
\hline TOTAL GENERAL & $1.853,6$ & 100,0 & 0,7 & 59,0 & $1.775,5$ & 100,0 & 0,6 & 25,3 \\
\hline Alimentación, bebidas y tabaco & 74,4 & 4,0 & 0,2 & 13,4 & 137,1 & 7,7 & 0,4 & 15,9 \\
\hline 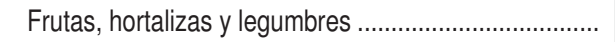 & 32,0 & 1,7 & 0,2 & 12,0 & 31,6 & 1,8 & 0,6 & 3,8 \\
\hline Resto de alimentos & 42,5 & 2,3 & 0,1 & 14,5 & 105,5 & 5,9 & 0,4 & 20,1 \\
\hline 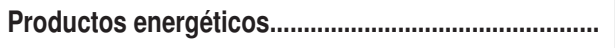 & 406,9 & 22,0 & 2,1 & 60,4 & 286,2 & 16,1 & 0,7 & 32,4 \\
\hline 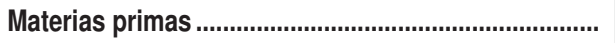 & 15,5 & 0,8 & 0,2 & $-10,8$ & 11,6 & 0,7 & 0,1 & 72,4 \\
\hline Semimanufacturas no químicas ................................... & 19,6 & 1,1 & 0,1 & $-16,2$ & 31,9 & 1,8 & 0,1 & $-4,3$ \\
\hline Hierro y acero & 0,5 & 0,0 & 0,0 & $-45,4$ & 2,4 & 0,1 & 0,0 & $-13,2$ \\
\hline Resto de semimanufacturas no químicas ....................... & 19,1 & 1,0 & 0,1 & $-14,9$ & 29,5 & 1,7 & 0,2 & $-3,5$ \\
\hline Productos químicos & 605,3 & 32,7 & 1,6 & 257,3 & 464,1 & 26,1 & 1,0 & 32,1 \\
\hline 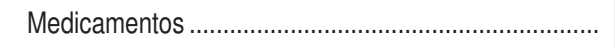 & 2,9 & 0,2 & 0,0 & 4,8 & 13,8 & 0,8 & 0,1 & $-26,2$ \\
\hline Resto de productos químicos & 602,5 & 32,5 & 2,1 & 261,5 & 450,3 & 25,4 & 1,4 & 35,4 \\
\hline Bienes de equipo & 396,7 & 21,4 & 0,7 & 24,3 & 527,7 & 29,7 & 0,8 & 32,3 \\
\hline 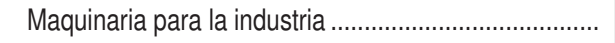 & 30,7 & 1,7 & 0,2 & 3,1 & 87,9 & 5,0 & 0,5 & 59,3 \\
\hline 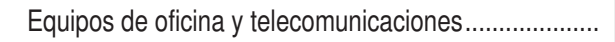 & 5,0 & 0,3 & 0,2 & $-12,3$ & 8,0 & 0,5 & 0,1 & $-27,1$ \\
\hline Material de transporte & 341,8 & 18,4 & 2,3 & 38,0 & 378,8 & 21,3 & 3,9 & 36,7 \\
\hline Resto de bienes de equipo & 19,3 & 1,0 & 0,1 & $-46,7$ & 53,0 & 3,0 & 0,2 & $-4,6$ \\
\hline 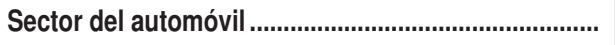 & 168,7 & 9,1 & 0,4 & 13,8 & 40,8 & 2,3 & 0,1 & 7,2 \\
\hline 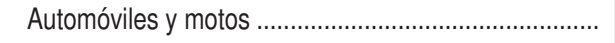 & 167,4 & 9,0 & 0,5 & 16,7 & 33,1 & 1,9 & 0,2 & 20,8 \\
\hline 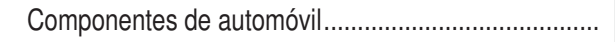 & 1,4 & 0,1 & 0,0 & $-71,6$ & 7,6 & 0,4 & 0,0 & $-28,1$ \\
\hline 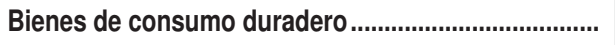 & 25,7 & 1,4 & 0,6 & $-14,9$ & 33,6 & 1,9 & 0,4 & 4,0 \\
\hline Manufacturas de consumo & 132,8 & 7,2 & 0,5 & 3,7 & 238,5 & 13,4 & 0,7 & 8,2 \\
\hline 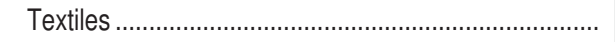 & 13,3 & 0,7 & 0,1 & 11,7 & 78,7 & 4,4 & 0,4 & 4,9 \\
\hline 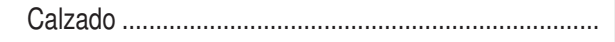 & 90,7 & 4,9 & 3,2 & 5,8 & 35,1 & 2,0 & 1,1 & 23,9 \\
\hline Resto de manufacturas de consumo ................................ & 28,7 & 1,6 & 0,3 & $-5,4$ & 124,7 & 7,0 & 1,0 & 6,6 \\
\hline 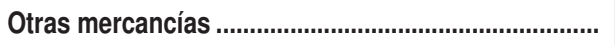 & 7,8 & 0,4 & 0,2 & $-23,9$ & 4,0 & 0,2 & 0,4 & 83,6 \\
\hline
\end{tabular}


4.6. CANARIAS. COMERCIO EXTERIOR EN 2017

(Millones de euros)

\begin{tabular}{|c|c|c|c|c|c|c|c|c|}
\hline \multirow[b]{2}{*}{ Sectores } & \multicolumn{4}{|c|}{ Exportaciones } & \multicolumn{4}{|c|}{ Importaciones } \\
\hline & Valor & $\begin{array}{l}\% \text { de } \\
\text { la CA }\end{array}$ & $\begin{array}{c}\% \text { de } \\
\text { España }\end{array}$ & $\begin{array}{c}\text { Crecim. } \\
17 / 16\end{array}$ & Valor & $\begin{array}{l}\% \text { de } \\
\text { la CA }\end{array}$ & $\begin{array}{c}\% \text { de } \\
\text { España }\end{array}$ & $\begin{array}{c}\text { Crecim. } \\
17 / 16\end{array}$ \\
\hline TOTAL GENERAL ................................................................. & $2.533,5$ & 100,0 & 0,9 & 26,6 & $4.301,0$ & 100,0 & 1,4 & 27,0 \\
\hline Alimentación, bebidas y tabaco................................... & 222,2 & 8,8 & 0,5 & 7,7 & 891,3 & 20,7 & 2,6 & 10,4 \\
\hline 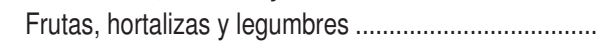 & 54,3 & 2,1 & 0,3 & $-5,8$ & 93,5 & 2,2 & 1,8 & 3,1 \\
\hline 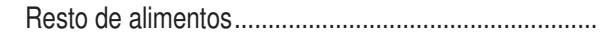 & 167,9 & 6,6 & 0,6 & 12,9 & 797,9 & 18,6 & 2,7 & 11,3 \\
\hline 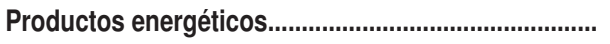 & $1.594,0$ & 62,9 & 8,1 & 34,9 & $1.037,8$ & 24,1 & 2,6 & 46,9 \\
\hline Materias primas & 34,3 & 1,4 & 0,5 & 47,1 & 33,6 & 0,8 & 0,3 & 14,5 \\
\hline Semimanufacturas no químicas ..................................... & 51,9 & 2,1 & 0,2 & 27,9 & 153,5 & 3,6 & 0,7 & 23,3 \\
\hline 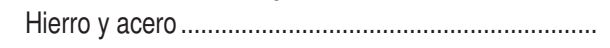 & 13,6 & 0,5 & 0,2 & 614,3 & 22,4 & 0,5 & 0,3 & 382,4 \\
\hline Resto de semimanufacturas no químicas .................... & 38,3 & 1,5 & 0,2 & $-1,0$ & 131,2 & 3,0 & 1,0 & 9,4 \\
\hline 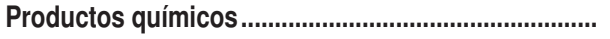 & 96,5 & 3,8 & 0,2 & 0,3 & 167,5 & 3,9 & 0,4 & 1,9 \\
\hline 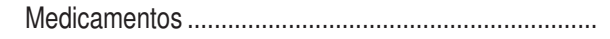 & 1,4 & 0,1 & 0,0 & $-10,3$ & 13,4 & 0,3 & 0,1 & $-5,0$ \\
\hline Resto de productos químicos & 95,2 & 3,8 & 0,3 & 0,5 & 154,1 & 3,6 & 0,5 & 2,5 \\
\hline 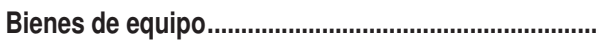 & 254,0 & 10,0 & 0,5 & 83,3 & $1.137,2$ & 26,4 & 1,8 & 60,6 \\
\hline 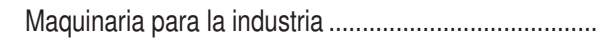 & 110,8 & 4,4 & 0,8 & 388,8 & 167,3 & 3,9 & 1,0 & $-1,3$ \\
\hline Equipos de oficina y telecomunicaciones..................... & 7,0 & 0,3 & 0,2 & $-24,7$ & 42,9 & 1,0 & 0,3 & $-11,8$ \\
\hline 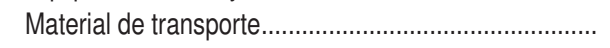 & 85,2 & 3,4 & 0,6 & 99,2 & 654,6 & 15,2 & 6,8 & 118,6 \\
\hline Resto de bienes de equipo & 51,0 & 2,0 & 0,2 & $-20,0$ & 272,4 & 6,3 & 1,0 & 43,2 \\
\hline 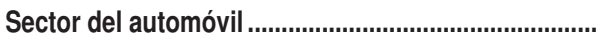 & 46,6 & 1,8 & 0,1 & $-12,5$ & 449,3 & 10,4 & 1,1 & 4,5 \\
\hline Automóviles y motos & 40,7 & 1,6 & 0,1 & 10,0 & 415,6 & 9,7 & 2,2 & 6,0 \\
\hline Componentes de automóvil.......................................... & 5,8 & 0,2 & 0,0 & $-64,0$ & 33,7 & 0,8 & 0,2 & $-11,0$ \\
\hline Bienes de consumo duradero ....................................... & 6,1 & 0,2 & 0,1 & 9,6 & 82,5 & 1,9 & 1,0 & 7,1 \\
\hline 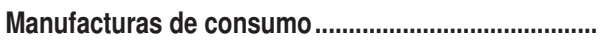 & 55,8 & 2,2 & 0,2 & $-5,2$ & 344,0 & 8,0 & 0,9 & 3,1 \\
\hline 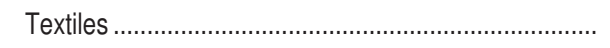 & 19,8 & 0,8 & 0,1 & 9,6 & 168,2 & 3,9 & 0,8 & 6,2 \\
\hline 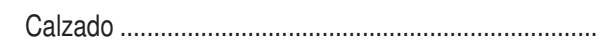 & 3,3 & 0,1 & 0,1 & 97,8 & 53,4 & 1,2 & 1,7 & $-3,3$ \\
\hline Resto de manufacturas de consumo .............................. & 32,7 & 1,3 & 0,4 & $-16,5$ & 122,5 & 2,8 & 1,0 & 2,0 \\
\hline Otras mercancías & 172,0 & 6,8 & 4,9 & $-12,4$ & 4,3 & 0,1 & 0,4 & $-17,1$ \\
\hline
\end{tabular}


4.7. CANTABRIA. COMERCIO EXTERIOR EN 2017

(Millones de euros)

\begin{tabular}{|c|c|c|c|c|c|c|c|c|}
\hline \multirow[b]{2}{*}{ Sectores } & \multicolumn{4}{|c|}{ Exportaciones } & \multicolumn{4}{|c|}{ Importaciones } \\
\hline & Valor & $\begin{array}{l}\% \text { de } \\
\text { la CA }\end{array}$ & $\begin{array}{l}\% \text { de } \\
\text { España }\end{array}$ & $\begin{array}{c}\text { Crecim. } \\
17 / 16\end{array}$ & Valor & $\begin{array}{l}\% \text { de } \\
\text { la CA }\end{array}$ & $\begin{array}{l}\% \text { de } \\
\text { España }\end{array}$ & $\begin{array}{c}\text { Crecim. } \\
17 / 16\end{array}$ \\
\hline TOTAL GENERAL & $2.319,2$ & 100,0 & 0,8 & $-1,0$ & $1.951,8$ & 100,0 & 0,6 & 7,9 \\
\hline Alimentación, bebidas y tabaco & 322,0 & 13,9 & 0,7 & 7,8 & 358,6 & 18,4 & 1,0 & 21,9 \\
\hline 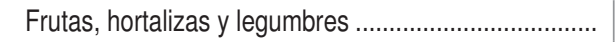 & 0,6 & 0,0 & 0,0 & $-76,1$ & 13,2 & 0,7 & 0,2 & 101,8 \\
\hline 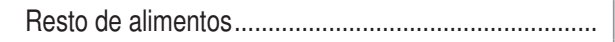 & 321,4 & 13,9 & 1,1 & 8,6 & 345,4 & 17,7 & 1,2 & 20,1 \\
\hline 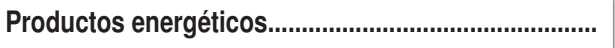 & 5,0 & 0,2 & 0,0 & $-11,1$ & 41,3 & 2,1 & 0,1 & $-25,4$ \\
\hline 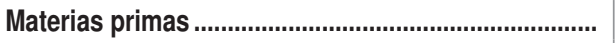 & 171,0 & 7,4 & 2,4 & $-8,1$ & 154,8 & 7,9 & 1,4 & 37,2 \\
\hline 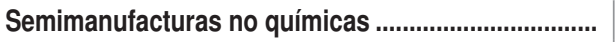 & 568,4 & 24,5 & 2,0 & 33,5 & 431,7 & 22,1 & 2,0 & 28,9 \\
\hline Hierro y acero & 467,4 & 20,2 & 6,0 & 37,7 & 202,7 & 10,4 & 2,5 & 65,1 \\
\hline Resto de semimanufacturas no químicas ....................... & 101,0 & 4,4 & 0,5 & 17,2 & 229,1 & 11,7 & 1,7 & 7,9 \\
\hline Productos químicos & 340,2 & 14,7 & 0,9 & 15,3 & 258,2 & 13,2 & 0,6 & 15,7 \\
\hline 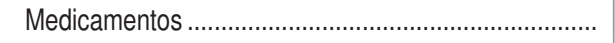 & 0,8 & 0,0 & 0,0 & 98,6 & 11,1 & 0,6 & 0,1 & $-7,3$ \\
\hline 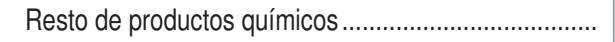 & 339,4 & 14,6 & 1,2 & 15,2 & 247,1 & 12,7 & 0,8 & 17,0 \\
\hline Bienes de equipo & 384,3 & 16,6 & 0,7 & $-33,5$ & 347,4 & 17,8 & 0,5 & $-4,4$ \\
\hline Maquinaria para la industria & 115,6 & 5,0 & 0,8 & $-8,2$ & 106,4 & 5,4 & 0,6 & $-1,3$ \\
\hline Equipos de oficina y telecomunicaciones.......................... & 9,2 & 0,4 & 0,3 & $-24,8$ & 33,8 & 1,7 & 0,3 & $-25,6$ \\
\hline 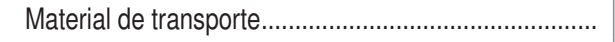 & 13,8 & 0,6 & 0,1 & 23,1 & 20,8 & 1,1 & 0,2 & 6,8 \\
\hline Resto de bienes de equipo & 245,7 & 10,6 & 1,0 & $-42,7$ & 186,3 & 9,5 & 0,7 & $-2,2$ \\
\hline 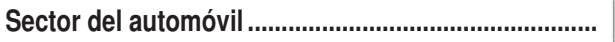 & 139,7 & 6,0 & 0,3 & $-24,1$ & 197,9 & 10,1 & 0,5 & $-24,5$ \\
\hline Automóviles y motos & 8,1 & 0,3 & 0,0 & $-78,8$ & 135,2 & 6,9 & 0,7 & $-34,1$ \\
\hline 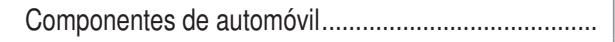 & 131,6 & 5,7 & 1,0 & $-9,8$ & 62,7 & 3,2 & 0,3 & 9,8 \\
\hline 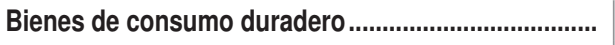 & 79,7 & 3,4 & 1,8 & 14,0 & 38,4 & 2,0 & 0,5 & 47,2 \\
\hline Manufacturas de consumo & 127,7 & 5,5 & 0,5 & 1,1 & 122,9 & 6,3 & 0,3 & $-10,2$ \\
\hline 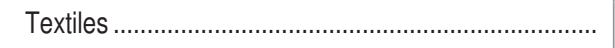 & 99,1 & 4,3 & 0,6 & 0,3 & 84,7 & 4,3 & 0,4 & $-16,9$ \\
\hline Calzado & 13,1 & 0,6 & 0,5 & 6,4 & 4,4 & 0,2 & 0,1 & $-1,0$ \\
\hline Resto de manufacturas de consumo & 15,5 & 0,7 & 0,2 & 2,0 & 33,8 & 1,7 & 0,3 & 10,9 \\
\hline Otras mercancías & 181,2 & 7,8 & 5,2 & 4,7 & 0,6 & 0,0 & 0,1 & $-1,4$ \\
\hline
\end{tabular}


4.8. CASTILLA Y LEÓN. COMERCIO EXTERIOR EN 2017

(Millones de euros)

\begin{tabular}{|c|c|c|c|c|c|c|c|c|}
\hline \multirow[b]{2}{*}{ Sectores } & \multicolumn{4}{|c|}{ Exportaciones } & \multicolumn{4}{|c|}{ Importaciones } \\
\hline & Valor & $\begin{array}{l}\% \text { de } \\
\text { la CA }\end{array}$ & $\begin{array}{c}\% \text { de } \\
\text { España }\end{array}$ & $\begin{array}{c}\text { Crecim. } \\
17 / 16\end{array}$ & Valor & $\begin{array}{l}\% \text { de } \\
\text { la CA }\end{array}$ & $\begin{array}{c}\% \text { de } \\
\text { España }\end{array}$ & $\begin{array}{c}\text { Crecim. } \\
17 / 16\end{array}$ \\
\hline TOTAL GENERAL ............................................................. & $15.597,6$ & 100,0 & 5,6 & $-3,9$ & $13.397,6$ & 100,0 & 4,4 & 5,7 \\
\hline Alimentación, bebidas y tabaco................................. & $1.844,4$ & 11,8 & 4,0 & 5,8 & $1.168,6$ & 8,7 & 3,4 & 16,9 \\
\hline 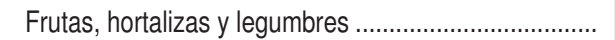 & 150,1 & 1,0 & 0,9 & $-2,7$ & 262,3 & 2,0 & 4,9 & 16,6 \\
\hline 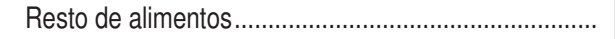 & $1.694,4$ & 10,9 & 5,9 & 6,6 & 906,3 & 6,8 & 3,1 & 17,0 \\
\hline 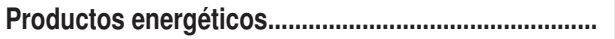 & 4,1 & 0,0 & 0,0 & 23,5 & 17,1 & 0,1 & 0,0 & $-16,4$ \\
\hline Materias primas & 147,4 & 0,9 & 2,1 & 8,5 & 297,1 & 2,2 & 2,8 & 11,5 \\
\hline 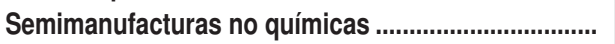 & $1.633,3$ & 10,5 & 5,8 & 4,4 & $1.252,2$ & 9,3 & 5,8 & 8,6 \\
\hline Hierro y acero & 365,0 & 2,3 & 4,7 & 8,4 & 509,0 & 3,8 & 6,3 & 10,1 \\
\hline Resto de semimanufacturas no químicas .................... & $1.268,2$ & 8,1 & 6,3 & 3,3 & 743,2 & 5,5 & 5,5 & 7,7 \\
\hline 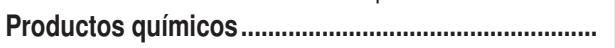 & $1.391,1$ & 8,9 & 3,6 & $-12,1$ & $1.684,3$ & 12,6 & 3,7 & $-6,9$ \\
\hline 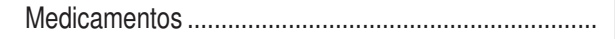 & 775,3 & 5,0 & 7,3 & $-19,4$ & 581,4 & 4,3 & 4,5 & $-18,6$ \\
\hline 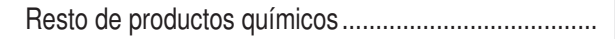 & 615,9 & 3,9 & 2,2 & $-0,7$ & $1.103,0$ & 8,2 & 3,5 & 0,8 \\
\hline 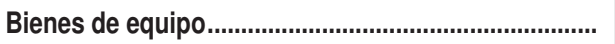 & $2.202,7$ & 14,1 & 3,9 & $-6,4$ & $3.707,7$ & 27,7 & 5,7 & 22,5 \\
\hline 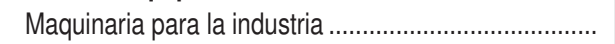 & 501,0 & 3,2 & 3,5 & 28,3 & $1.735,7$ & 13,0 & 10,3 & 21,8 \\
\hline Equipos de oficina y telecomunicaciones...................... & 15,6 & 0,1 & 0,5 & $-6,2$ & 129,8 & 1,0 & 1,0 & 9,9 \\
\hline 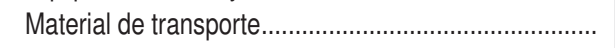 & 483,3 & 3,1 & 3,2 & $-2,2$ & 427,7 & 3,2 & 4,4 & 10,1 \\
\hline 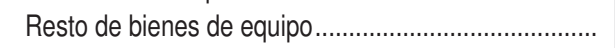 & $1.202,8$ & 7,7 & 5,0 & $-17,2$ & $1.414,4$ & 10,6 & 5,4 & 29,3 \\
\hline 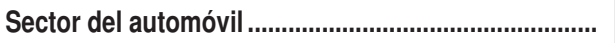 & $7.621,1$ & 48,9 & 16,9 & $-4,7$ & $4.515,8$ & 33,7 & 11,6 & $-0,7$ \\
\hline Automóviles y motos .................................................. & $5.204,2$ & 33,4 & 16,1 & $-7,4$ & 765,5 & 5,7 & 4,0 & $-3,3$ \\
\hline 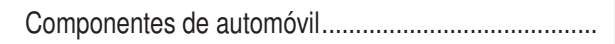 & $2.416,9$ & 15,5 & 18,7 & 1,6 & $3.750,3$ & 28,0 & 18,8 & $-0,1$ \\
\hline 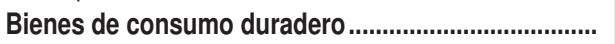 & 107,4 & 0,7 & 2,4 & $-16,9$ & 354,5 & 2,6 & 4,4 & $-18,1$ \\
\hline 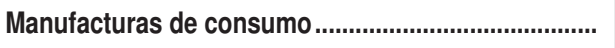 & 433,9 & 2,8 & 1,5 & 80,7 & 398,6 & 3,0 & 1,1 & 2,7 \\
\hline 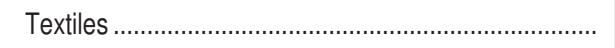 & 72,3 & 0,5 & 0,4 & 35,0 & 194,7 & 1,5 & 0,9 & $-1,0$ \\
\hline 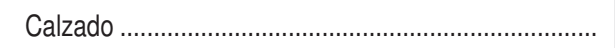 & 1,3 & 0,0 & 0,0 & $-10,9$ & 11,9 & 0,1 & 0,4 & 13,1 \\
\hline 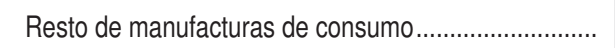 & 360,4 & 2,3 & 4,3 & 94,6 & 192,0 & 1,4 & 1,6 & 6,0 \\
\hline Otras mercancías & 212,0 & 1,4 & 6,0 & $-55,9$ & 1,7 & 0,0 & 0,2 & $-95,7$ \\
\hline
\end{tabular}


4.9. CASTILLA-LA MANCHA. COMERCIO EXTERIOR EN 2017

(Millones de euros)

\begin{tabular}{|c|c|c|c|c|c|c|c|c|}
\hline \multirow[b]{2}{*}{ Sectores } & \multicolumn{4}{|c|}{ Exportaciones } & \multicolumn{4}{|c|}{ Importaciones } \\
\hline & Valor & $\begin{array}{l}\% \text { de } \\
\text { la CA }\end{array}$ & $\begin{array}{l}\% \text { de } \\
\text { España }\end{array}$ & $\begin{array}{c}\text { Crecim. } \\
17 / 16\end{array}$ & Valor & $\begin{array}{l}\% \text { de } \\
\text { la CA }\end{array}$ & $\begin{array}{l}\% \text { de } \\
\text { España }\end{array}$ & $\begin{array}{c}\text { Crecim. } \\
17 / 16\end{array}$ \\
\hline TOTAL GENERAL & $7.056,1$ & 100,0 & 2,5 & 9,3 & $8.432,2$ & 100,0 & 2,8 & 11,0 \\
\hline Alimentación, bebidas y tabaco & $2.460,2$ & 34,9 & 5,4 & 9,4 & $1.412,2$ & 16,7 & 4,1 & 5,3 \\
\hline 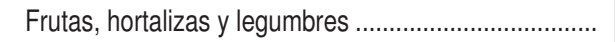 & 392,1 & 5,6 & 2,3 & 0,8 & 154,4 & 1,8 & 2,9 & 8,1 \\
\hline 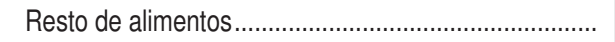 & $2.068,1$ & 29,3 & 7,2 & 11,2 & $1.257,8$ & 14,9 & 4,3 & 5,0 \\
\hline 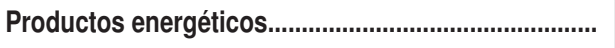 & 55,5 & 0,8 & 0,3 & 42,4 & 18,7 & 0,2 & 0,0 & 3,3 \\
\hline 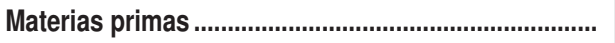 & 63,2 & 0,9 & 0,9 & 15,0 & 69,6 & 0,8 & 0,6 & 6,1 \\
\hline 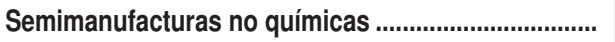 & 672,5 & 9,5 & 2,4 & 11,5 & 782,7 & 9,3 & 3,6 & 10,3 \\
\hline Hierro y acero & 31,9 & 0,5 & 0,4 & 63,5 & 120,8 & 1,4 & 1,5 & 41,4 \\
\hline Resto de semimanufacturas no químicas ....................... & 640,6 & 9,1 & 3,2 & 9,8 & 661,9 & 7,8 & 4,9 & 6,1 \\
\hline Productos químicos & $1.018,6$ & 14,4 & 2,6 & 10,1 & $1.647,2$ & 19,5 & 3,7 & 26,2 \\
\hline 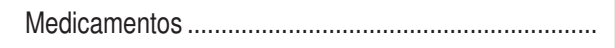 & 117,7 & 1,7 & 1,1 & 19,1 & 756,9 & 9,0 & 5,8 & 60,9 \\
\hline 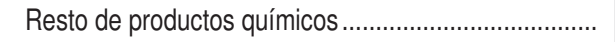 & 901,0 & 12,8 & 3,2 & 9,1 & 890,4 & 10,6 & 2,8 & 6,6 \\
\hline Bienes de equipo & $1.500,5$ & 21,3 & 2,7 & 23,6 & $2.697,7$ & 32,0 & 4,2 & 8,9 \\
\hline Maquinaria para la industria & 267,6 & 3,8 & 1,9 & 22,9 & 504,6 & 6,0 & 3,0 & 7,6 \\
\hline 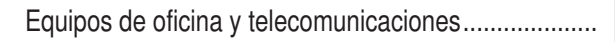 & 258,7 & 3,7 & 8,3 & 49,7 & 990,2 & 11,7 & 8,0 & 16,0 \\
\hline Material de transporte. & 94,4 & 1,3 & 0,6 & 14,7 & 444,8 & 5,3 & 4,6 & 12,7 \\
\hline Resto de bienes de equipo & 879,9 & 12,5 & 3,7 & 18,7 & 758,1 & 9,0 & 2,9 & $-0,3$ \\
\hline 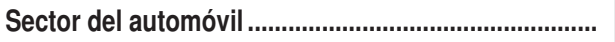 & 135,7 & 1,9 & 0,3 & 0,8 & 266,6 & 3,2 & 0,7 & 26,6 \\
\hline Automóviles y motos & 12,3 & 0,2 & 0,0 & $-23,0$ & 19,0 & 0,2 & 0,1 & 23,5 \\
\hline 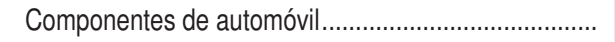 & 123,4 & 1,7 & 1,0 & 4,0 & 247,6 & 2,9 & 1,2 & 26,9 \\
\hline 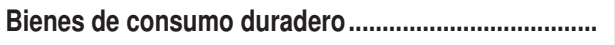 & 104,0 & 1,5 & 2,3 & 9,5 & 319,0 & 3,8 & 4,0 & 23,0 \\
\hline Manufacturas de consumo & $1.029,1$ & 14,6 & 3,6 & $-8,6$ & $1.217,5$ & 14,4 & 3,3 & 1,0 \\
\hline 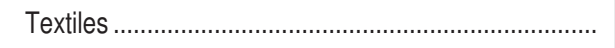 & 598,0 & 8,5 & 3,5 & $-7,2$ & 838,1 & 9,9 & 3,9 & 3,0 \\
\hline 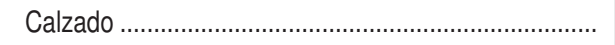 & 178,1 & 2,5 & 6,3 & $-8,0$ & 47,1 & 0,6 & 1,5 & $-17,2$ \\
\hline Resto de manufacturas de consumo & 253,1 & 3,6 & 3,0 & $-12,0$ & 332,3 & 3,9 & 2,7 & $-0,7$ \\
\hline Otras mercancías & 16,7 & 0,2 & 0,5 & 6,5 & 0,9 & 0,0 & 0,1 & $-55,9$ \\
\hline
\end{tabular}


4.10. CATALUÑA. COMERCIO EXTERIOR EN 2017

(Millones de euros)

\begin{tabular}{|c|c|c|c|c|c|c|c|c|}
\hline \multirow[b]{2}{*}{ Sectores } & \multicolumn{4}{|c|}{ Exportaciones } & \multicolumn{4}{|c|}{ Importaciones } \\
\hline & Valor & $\begin{array}{l}\% \text { de } \\
\text { la CA }\end{array}$ & $\begin{array}{l}\% \text { de } \\
\text { España }\end{array}$ & $\begin{array}{c}\text { Crecim. } \\
17 / 16\end{array}$ & Valor & $\begin{array}{l}\% \text { de } \\
\text { la CA }\end{array}$ & $\begin{array}{l}\% \text { de } \\
\text { España }\end{array}$ & $\begin{array}{c}\text { Crecim. } \\
17 / 16\end{array}$ \\
\hline TOTAL GENERAL & $70.828,7$ & 100,0 & 25,6 & 8,7 & $84.321,7$ & 100,0 & 27,9 & 8,3 \\
\hline Alimentación, bebidas y tabaco & $9.688,8$ & 13,7 & 21,2 & 4,5 & $9.767,4$ & 11,6 & 28,2 & 4,1 \\
\hline 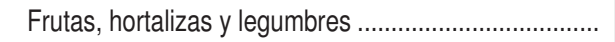 & $1.345,9$ & 1,9 & 7,8 & 2,4 & $1.092,3$ & 1,3 & 20,6 & 3,9 \\
\hline Resto de alimentos & $8.342,9$ & 11,8 & 29,2 & 4,8 & $8.675,1$ & 10,3 & 29,6 & 4,2 \\
\hline 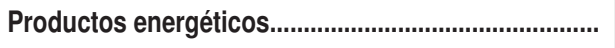 & $3.504,9$ & 4,9 & 17,9 & 86,9 & $6.924,8$ & 8,2 & 17,2 & 39,1 \\
\hline 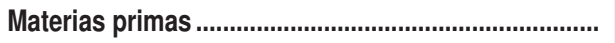 & $1.146,3$ & 1,6 & 16,1 & 25,5 & $1.345,2$ & 1,6 & 12,5 & 9,7 \\
\hline 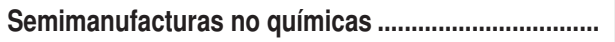 & $4.608,2$ & 6,5 & 16,4 & 10,1 & $5.013,7$ & 5,9 & 23,3 & 13,8 \\
\hline Hierro y acero & $1.194,2$ & 1,7 & 15,3 & 26,9 & $1.650,4$ & 2,0 & 20,3 & 24,5 \\
\hline Resto de semimanufacturas no químicas ....................... & $3.413,9$ & 4,8 & 16,8 & 5,3 & $3.363,3$ & 4,0 & 25,1 & 9,2 \\
\hline Productos químicos & $18.175,1$ & 25,7 & 46,8 & 7,0 & $17.784,9$ & 21,1 & 39,6 & 7,9 \\
\hline 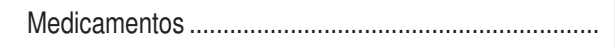 & $4.861,6$ & 6,9 & 45,6 & 5,4 & $3.719,4$ & 4,4 & 28,6 & 0,8 \\
\hline Resto de productos químicos & $13.313,5$ & 18,8 & 47,3 & 7,6 & $14.065,5$ & 16,7 & 44,1 & 9,9 \\
\hline Bienes de equipo & $12.422,2$ & 17,5 & 22,0 & 2,7 & $15.005,2$ & 17,8 & 23,1 & 2,7 \\
\hline 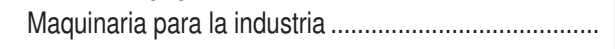 & $4.246,8$ & 6,0 & 29,8 & 5,3 & $4.757,9$ & 5,6 & 28,3 & 1,2 \\
\hline 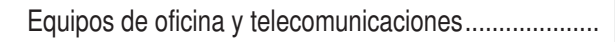 & 631,4 & 0,9 & 20,3 & $-8,3$ & $1.903,7$ & 2,3 & 15,3 & 5,4 \\
\hline Material de transporte. & $1.413,1$ & 2,0 & 9,3 & $-3,9$ & 504,4 & 0,6 & 5,2 & 2,9 \\
\hline Resto de bienes de equipo & $6.130,9$ & 8,7 & 25,7 & 3,8 & $7.839,1$ & 9,3 & 30,2 & 3,0 \\
\hline 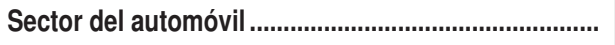 & $10.959,1$ & 15,5 & 24,3 & 5,8 & $12.661,9$ & 15,0 & 32,4 & 5,7 \\
\hline 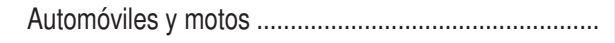 & $8.332,0$ & 11,8 & 25,9 & 3,9 & $8.715,4$ & 10,3 & 45,5 & 7,4 \\
\hline 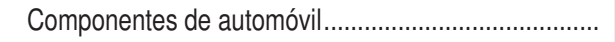 & $2.627,0$ & 3,7 & 20,3 & 12,3 & $3.946,4$ & 4,7 & 19,8 & 2,2 \\
\hline 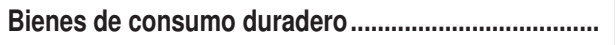 & $1.056,6$ & 1,5 & 23,6 & 5,0 & $2.653,4$ & 3,1 & 33,0 & 3,2 \\
\hline Manufacturas de consumo & $8.860,2$ & 12,5 & 31,4 & 10,3 & $13.110,5$ & 15,5 & 35,8 & 8,3 \\
\hline 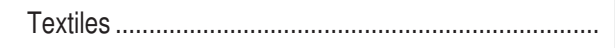 & $5.089,7$ & 7,2 & 30,1 & 5,7 & $7.864,0$ & 9,3 & 37,0 & 3,4 \\
\hline 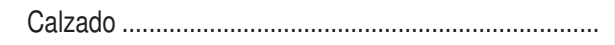 & 259,3 & 0,4 & 9,2 & 4,5 & 863,2 & 1,0 & 27,6 & 10,2 \\
\hline 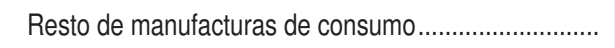 & $3.511,2$ & 5,0 & 41,6 & 18,3 & $4.383,3$ & 5,2 & 35,9 & 17,9 \\
\hline 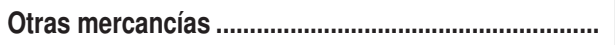 & 407,3 & 0,6 & 11,6 & $-0,7$ & 54,7 & 0,1 & 5,0 & $-32,4$ \\
\hline
\end{tabular}


4.11. COMUNITAT VALENCIANA. COMERCIO EXTERIOR EN 2017

(Millones de euros)

\begin{tabular}{|c|c|c|c|c|c|c|c|c|}
\hline \multirow[b]{2}{*}{ Sectores } & \multicolumn{4}{|c|}{ Exportaciones } & \multicolumn{4}{|c|}{ Importaciones } \\
\hline & Valor & $\begin{array}{l}\% \text { de } \\
\text { la CA }\end{array}$ & $\begin{array}{l}\% \text { de } \\
\text { España }\end{array}$ & $\begin{array}{c}\text { Crecim. } \\
17 / 16\end{array}$ & Valor & $\begin{array}{l}\% \text { de } \\
\text { la CA }\end{array}$ & $\begin{array}{c}\% \text { de } \\
\text { España }\end{array}$ & $\begin{array}{c}\text { Crecim. } \\
17 / 16\end{array}$ \\
\hline TOTAL GENERAL & $29.371,0$ & 100,0 & 10,6 & 2,4 & $26.027,7$ & 100,0 & 8,6 & 9,0 \\
\hline 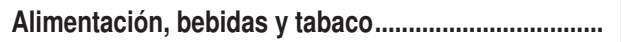 & $5.740,9$ & 19,5 & 12,5 & 3,8 & $3.644,4$ & 14,0 & 10,5 & 8,9 \\
\hline 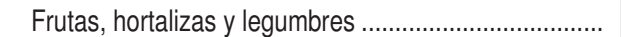 & $4.306,6$ & 14,7 & 25,0 & 1,5 & $1.126,9$ & 4,3 & 21,2 & $-3,9$ \\
\hline Resto de alimentos & $1.434,3$ & 4,9 & 5,0 & 11,3 & $2.517,5$ & 9,7 & 8,6 & 15,8 \\
\hline 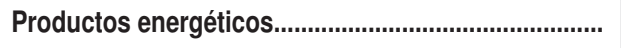 & 527,4 & 1,8 & 2,7 & 21,4 & $2.089,5$ & 8,0 & 5,2 & 10,3 \\
\hline Materias primas & 625,1 & 2,1 & 8,8 & 17,7 & 779,3 & 3,0 & 7,2 & 18,0 \\
\hline 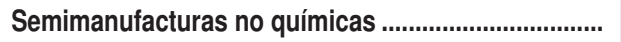 & $4.176,2$ & 14,2 & 14,9 & 3,2 & $2.630,8$ & 10,1 & 12,2 & 27,5 \\
\hline Hierro y acero & 381,5 & 1,3 & 4,9 & $-0,3$ & $1.023,6$ & 3,9 & 12,6 & 58,9 \\
\hline Resto de semimanufacturas no químicas ......................... & $3.794,8$ & 12,9 & 18,7 & 3,5 & $1.607,3$ & 6,2 & 12,0 & 13,2 \\
\hline Productos químicos....................................................... & $3.793,2$ & 12,9 & 9,8 & 4,6 & $3.297,0$ & 12,7 & 7,3 & 8,1 \\
\hline 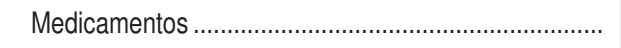 & 50,1 & 0,2 & 0,5 & 2,4 & 153,4 & 0,6 & 1,2 & $-25,7$ \\
\hline Resto de productos químicos & $3.743,1$ & 12,7 & 13,3 & 4,6 & $3.143,6$ & 12,1 & 9,8 & 10,5 \\
\hline 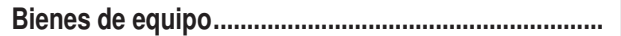 & $3.070,7$ & 10,5 & 5,4 & 6,5 & $4.264,8$ & 16,4 & 6,6 & 4,2 \\
\hline 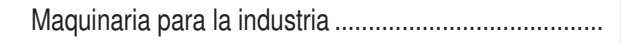 & 963,5 & 3,3 & 6,7 & 10,8 & $1.504,9$ & 5,8 & 9,0 & 0,6 \\
\hline Equipos de oficina y telecomunicaciones........................ & 201,8 & 0,7 & 6,5 & $-18,2$ & 371,5 & 1,4 & 3,0 & $-5,5$ \\
\hline Material de transporte & 937,5 & 3,2 & 6,2 & 21,7 & 591,0 & 2,3 & 6,1 & 6,0 \\
\hline Resto de bienes de equipo & 967,9 & 3,3 & 4,1 & $-3,0$ & $1.797,4$ & 6,9 & 6,9 & 9,2 \\
\hline 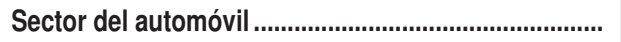 & $7.662,2$ & 26,1 & 17,0 & $-2,1$ & $5.046,1$ & 19,4 & 12,9 & 6,8 \\
\hline Automóviles y motos & $6.515,3$ & 22,2 & 20,2 & 1,5 & $2.300,3$ & 8,8 & 12,0 & 14,9 \\
\hline Componentes de automóvil.......................................... & $1.146,9$ & 3,9 & 8,9 & $-18,4$ & $2.745,8$ & 10,5 & 13,8 & 0,9 \\
\hline 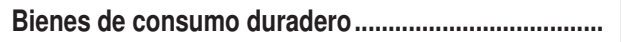 & 608,5 & 2,1 & 13,6 & $-1,0$ & 921,2 & 3,5 & 11,5 & 13,9 \\
\hline Manufacturas de consumo & $3.048,9$ & 10,4 & 10,8 & $-0,3$ & $3.337,9$ & 12,8 & 9,1 & 3,7 \\
\hline 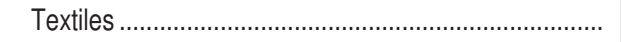 & 895,5 & 3,0 & 5,3 & 2,7 & $1.135,1$ & 4,4 & 5,3 & 10,4 \\
\hline Calzado & $1.212,5$ & 4,1 & 42,9 & $-2,9$ & 845,3 & 3,2 & 27,1 & 1,6 \\
\hline Resto de manufacturas de consumo $\ldots \ldots \ldots \ldots \ldots \ldots \ldots \ldots \ldots$ & 940,9 & 3,2 & 11,2 & 0,4 & $1.357,5$ & 5,2 & 11,1 & 0,0 \\
\hline Otras mercancías & 117,9 & 0,4 & 3,4 & $-6,2$ & 16,6 & 0,1 & 1,5 & $-6,9$ \\
\hline
\end{tabular}


4.12. EXTREMADURA. COMERCIO EXTERIOR EN 2017

(Millones de euros)

\begin{tabular}{|c|c|c|c|c|c|c|c|c|}
\hline \multirow[b]{2}{*}{ Sectores } & \multicolumn{4}{|c|}{ Exportaciones } & \multicolumn{4}{|c|}{ Importaciones } \\
\hline & Valor & $\begin{array}{l}\% \text { de } \\
\text { la CA }\end{array}$ & $\begin{array}{l}\% \text { de } \\
\text { España }\end{array}$ & $\begin{array}{c}\text { Crecim. } \\
17 / 16\end{array}$ & Valor & $\begin{array}{l}\% \text { de } \\
\text { la CA }\end{array}$ & $\begin{array}{l}\% \text { de } \\
\text { España }\end{array}$ & $\begin{array}{c}\text { Crecim. } \\
17 / 16\end{array}$ \\
\hline TOTAL GENERAL & $1.919,0$ & 100,0 & 0,7 & 14,1 & $1.205,6$ & 100,0 & 0,4 & 12,5 \\
\hline Alimentación, bebidas y tabaco & $1.002,0$ & 52,2 & 2,2 & 6,4 & 235,5 & 19,5 & 0,7 & 8,1 \\
\hline 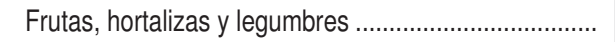 & 507,4 & 26,4 & 2,9 & $-2,3$ & 43,3 & 3,6 & 0,8 & $-13,1$ \\
\hline 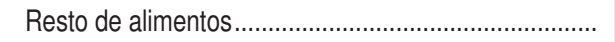 & 494,6 & 25,8 & 1,7 & 17,2 & 192,2 & 15,9 & 0,7 & 14,4 \\
\hline 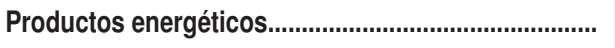 & 6,9 & 0,4 & 0,0 & 55,2 & 15,1 & 1,3 & 0,0 & 15,0 \\
\hline 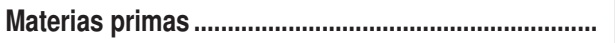 & 107,6 & 5,6 & 1,5 & 14,1 & 157,1 & 13,0 & 1,5 & 35,1 \\
\hline 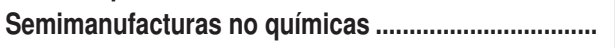 & 350,6 & 18,3 & 1,2 & 39,6 & 136,7 & 11,3 & 0,6 & 31,6 \\
\hline Hierro y acero & 160,3 & 8,4 & 2,1 & 68,0 & 44,2 & 3,7 & 0,5 & 123,9 \\
\hline Resto de semimanufacturas no químicas ....................... & 190,3 & 9,9 & 0,9 & 22,3 & 92,5 & 7,7 & 0,7 & 9,9 \\
\hline Productos químicos & 120,8 & 6,3 & 0,3 & 34,5 & 111,2 & 9,2 & 0,2 & 4,3 \\
\hline 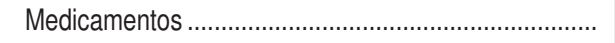 & 18,9 & 1,0 & 0,2 & $1.567,0$ & 2,3 & 0,2 & 0,0 & $-4,2$ \\
\hline 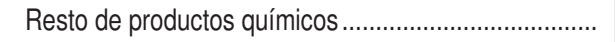 & 101,9 & 5,3 & 0,4 & 14,9 & 108,9 & 9,0 & 0,3 & 4,5 \\
\hline 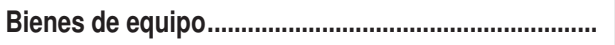 & 82,1 & 4,3 & 0,1 & 19,7 & 289,1 & 24,0 & 0,4 & 14,8 \\
\hline Maquinaria para la industria & 15,5 & 0,8 & 0,1 & 4,4 & 49,2 & 4,1 & 0,3 & $-4,0$ \\
\hline 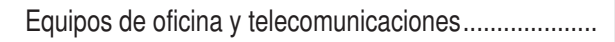 & 0,5 & 0,0 & 0,0 & 116,1 & 190,6 & 15,8 & 1,5 & 18,0 \\
\hline 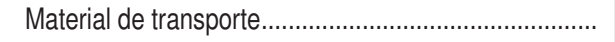 & 1,3 & 0,1 & 0,0 & 12,4 & 8,8 & 0,7 & 0,1 & $-19,7$ \\
\hline Resto de bienes de equipo & 64,8 & 3,4 & 0,3 & 23,8 & 40,5 & 3,4 & 0,2 & 44,4 \\
\hline 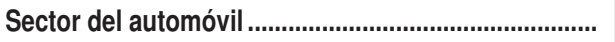 & 110,3 & 5,7 & 0,2 & 31,8 & 84,9 & 7,0 & 0,2 & 12,3 \\
\hline Automóviles y motos & 0,2 & 0,0 & 0,0 & 19,3 & 10,4 & 0,9 & 0,1 & 20,3 \\
\hline 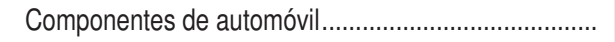 & 110,1 & 5,7 & 0,9 & 31,8 & 74,6 & 6,2 & 0,4 & 11,3 \\
\hline 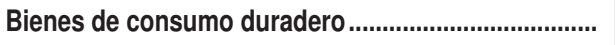 & 14,6 & 0,8 & 0,3 & $-2,7$ & 23,6 & 2,0 & 0,3 & 3,9 \\
\hline Manufacturas de consumo & 123,8 & 6,5 & 0,4 & $-2,8$ & 152,0 & 12,6 & 0,4 & $-6,5$ \\
\hline 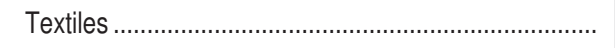 & 42,6 & 2,2 & 0,3 & 2,4 & 14,3 & 1,2 & 0,1 & $-18,6$ \\
\hline 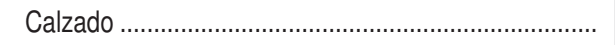 & 1,0 & 0,1 & 0,0 & $-32,0$ & 3,9 & 0,3 & 0,1 & 9,8 \\
\hline Resto de manufacturas de consumo & 80,2 & 4,2 & 1,0 & $-4,9$ & 133,8 & 11,1 & 1,1 & $-5,4$ \\
\hline Otras mercancías & 0,3 & 0,0 & 0,0 & $-94,5$ & 0,4 & 0,0 & 0,0 & $-51,9$ \\
\hline
\end{tabular}


4.13. GALICIA. COMERCIO EXTERIOR EN 2017

(Millones de euros)

\begin{tabular}{|c|c|c|c|c|c|c|c|c|}
\hline \multirow[b]{2}{*}{ Sectores } & \multicolumn{4}{|c|}{ Exportaciones } & \multicolumn{4}{|c|}{ Importaciones } \\
\hline & Valor & $\begin{array}{l}\% \text { de } \\
\text { la CA }\end{array}$ & $\begin{array}{l}\% \text { de } \\
\text { España }\end{array}$ & $\begin{array}{c}\text { Crecim. } \\
17 / 16\end{array}$ & Valor & $\begin{array}{l}\% \text { de } \\
\text { la CA }\end{array}$ & $\begin{array}{l}\% \text { de } \\
\text { España }\end{array}$ & $\begin{array}{c}\text { Crecim. } \\
17 / 16\end{array}$ \\
\hline TOTAL GENERAL & $21.676,3$ & 100,0 & 7,8 & 8,2 & $17.140,8$ & 100,0 & 5,7 & 10,0 \\
\hline Alimentación, bebidas y tabaco & $2.889,0$ & 13,3 & 6,3 & 8,7 & $3.540,2$ & 20,7 & 10,2 & 9,8 \\
\hline 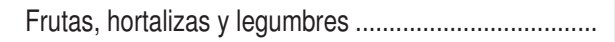 & 79,3 & 0,4 & 0,5 & $-22,8$ & 72,7 & 0,4 & 1,4 & $-3,3$ \\
\hline Resto de alimentos & $2.809,8$ & 13,0 & 9,8 & 10,0 & $3.467,4$ & 20,2 & 11,8 & 10,1 \\
\hline 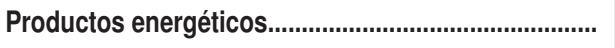 & $1.558,8$ & 7,2 & 7,9 & 74,2 & $2.592,0$ & 15,1 & 6,4 & 55,5 \\
\hline 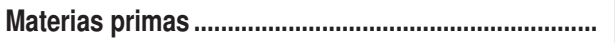 & 725,0 & 3,3 & 10,2 & $-1,2$ & 467,0 & 2,7 & 4,3 & 9,7 \\
\hline 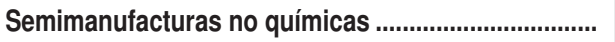 & $1.806,5$ & 8,3 & 6,4 & 18,3 & $1.293,1$ & 7,5 & 6,0 & 8,3 \\
\hline Hierro y acero & 437,5 & 2,0 & 5,6 & 51,9 & 576,4 & 3,4 & 7,1 & 14,2 \\
\hline Resto de semimanufacturas no químicas ....................... & $1.369,0$ & 6,3 & 6,8 & 10,4 & 716,7 & 4,2 & 5,4 & 3,9 \\
\hline Productos químicos & 860,2 & 4,0 & 2,2 & 6,0 & 768,1 & 4,5 & 1,7 & 19,4 \\
\hline 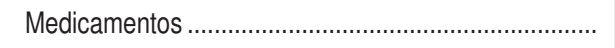 & 42,5 & 0,2 & 0,4 & 7,1 & 47,8 & 0,3 & 0,4 & $-7,7$ \\
\hline 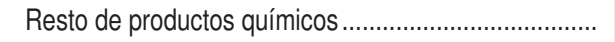 & 817,7 & 3,8 & 2,9 & 6,0 & 720,4 & 4,2 & 2,3 & 21,8 \\
\hline Bienes de equipo & $3.156,2$ & 14,6 & 5,6 & 0,7 & $1.430,5$ & 8,3 & 2,2 & $-2,0$ \\
\hline Maquinaria para la industria & 453,7 & 2,1 & 3,2 & 2,3 & 506,2 & 3,0 & 3,0 & $-5,1$ \\
\hline 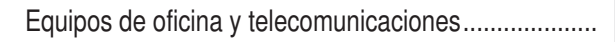 & 88,5 & 0,4 & 2,8 & 42,1 & 98,1 & 0,6 & 0,8 & 30,8 \\
\hline 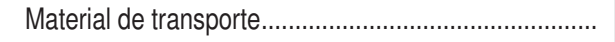 & $1.844,3$ & 8,5 & 12,2 & 3,3 & 273,4 & 1,6 & 2,8 & $-11,7$ \\
\hline Resto de bienes de equipo & 769,7 & 3,6 & 3,2 & $-8,9$ & 552,8 & 3,2 & 2,1 & 2,1 \\
\hline 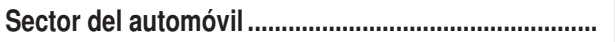 & $3.552,2$ & 16,4 & 7,9 & $-7,7$ & $4.751,4$ & 27,7 & 12,2 & 9,4 \\
\hline Automóviles y motos & $2.858,6$ & 13,2 & 8,9 & $-10,5$ & $1.797,3$ & 10,5 & 9,4 & 10,2 \\
\hline 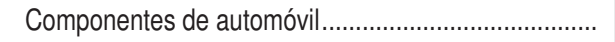 & 693,6 & 3,2 & 5,4 & 6,5 & $2.954,2$ & 17,2 & 14,8 & 8,8 \\
\hline Bienes de consumo duradero & 275,3 & 1,3 & 6,1 & 21,5 & 220,9 & 1,3 & 2,7 & 6,0 \\
\hline Manufacturas de consumo & $6.701,5$ & 30,9 & 23,8 & 10,5 & $2.070,8$ & 12,1 & 5,7 & $-14,1$ \\
\hline 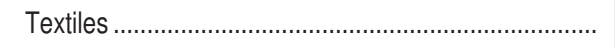 & $5.970,8$ & 27,5 & 35,3 & 10,7 & $1.833,3$ & 10,7 & 8,6 & $-15,1$ \\
\hline 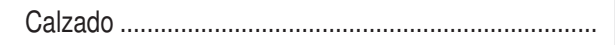 & 438,0 & 2,0 & 15,5 & 9,4 & 78,2 & 0,5 & 2,5 & $-4,2$ \\
\hline Resto de manufacturas de consumo & 292,7 & 1,4 & 3,5 & 7,8 & 159,3 & 0,9 & 1,3 & $-5,6$ \\
\hline Otras mercancías & 151,5 & 0,7 & 4,3 & 10,3 & 6,9 & 0,0 & 0,6 & $-15,8$ \\
\hline
\end{tabular}


4.14. MADRID, COMUNIDAD DE. COMERCIO EXTERIOR EN 2017

(Millones de euros)

\begin{tabular}{|c|c|c|c|c|c|c|c|c|}
\hline \multirow[b]{2}{*}{ Sectores } & \multicolumn{4}{|c|}{ Exportaciones } & \multicolumn{4}{|c|}{ Importaciones } \\
\hline & Valor & $\begin{array}{l}\% \text { de } \\
\text { la CA }\end{array}$ & $\begin{array}{c}\% \text { de } \\
\text { España }\end{array}$ & $\begin{array}{c}\text { Crecim. } \\
17 / 16\end{array}$ & Valor & $\begin{array}{l}\% \text { de } \\
\text { la CA }\end{array}$ & $\begin{array}{c}\% \text { de } \\
\text { España }\end{array}$ & $\begin{array}{c}\text { Crecim. } \\
17 / 16\end{array}$ \\
\hline TOTAL GENERAL ................................................................. & $30.510,3$ & 100,0 & 11,0 & 7,8 & $60.884,6$ & 100,0 & 20,2 & 5,6 \\
\hline Alimentación, bebidas y tabaco................................... & $1.523,1$ & 5,0 & 3,3 & 0,7 & $4.333,2$ & 7,1 & 12,5 & 7,9 \\
\hline 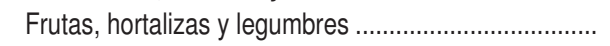 & 404,2 & 1,3 & 2,3 & 5,1 & 479,7 & 0,8 & 9,0 & 14,5 \\
\hline 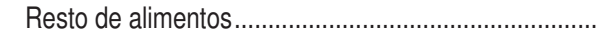 & $1.118,9$ & 3,7 & 3,9 & $-0,8$ & $3.853,5$ & 6,3 & 13,1 & 7,1 \\
\hline 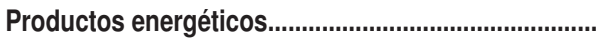 & $2.296,9$ & 7,5 & 11,7 & 42,0 & $2.647,2$ & 4,3 & 6,6 & 41,4 \\
\hline Materias primas & 366,4 & 1,2 & 5,1 & 83,8 & 396,3 & 0,7 & 3,7 & 7,4 \\
\hline Semimanufacturas no químicas ..................................... & $1.545,4$ & 5,1 & 5,5 & 2,9 & $2.957,3$ & 4,9 & 13,7 & 9,4 \\
\hline Hierro y acero & 176,6 & 0,6 & 2,3 & 29,7 & 845,8 & 1,4 & 10,4 & 31,3 \\
\hline Resto de semimanufacturas no químicas .................... & $1.368,8$ & 4,5 & 6,8 & 0,3 & $2.111,6$ & 3,5 & 15,8 & 2,5 \\
\hline 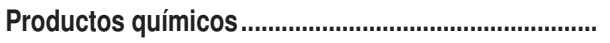 & $6.703,5$ & 22,0 & 17,3 & 4,5 & $12.253,4$ & 20,1 & 27,3 & $-1,7$ \\
\hline 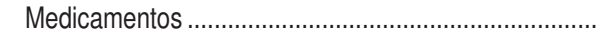 & $4.478,0$ & 14,7 & 42,0 & 4,6 & $7.470,2$ & 12,3 & 57,4 & $-2,9$ \\
\hline Resto de productos químicos & $2.225,4$ & 7,3 & 7,9 & 4,3 & $4.783,2$ & 7,9 & 15,0 & 0,2 \\
\hline 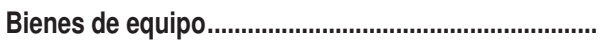 & $11.650,3$ & 38,2 & 20,7 & 6,4 & $21.222,1$ & 34,9 & 32,7 & 7,2 \\
\hline 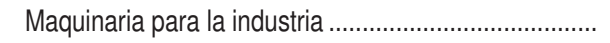 & $1.851,8$ & 6,1 & 13,0 & 7,5 & $3.527,9$ & 5,8 & 21,0 & 5,9 \\
\hline Equipos de oficina y telecomunicaciones...................... & $1.449,6$ & 4,8 & 46,7 & 23,2 & $7.501,8$ & 12,3 & 60,3 & 4,9 \\
\hline Material de transporte & $3.740,9$ & 12,3 & 24,7 & $-15,6$ & $3.597,1$ & 5,9 & 37,4 & 9,5 \\
\hline 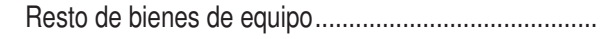 & $4.607,9$ & 15,1 & 19,3 & 27,4 & $6.595,3$ & 10,8 & 25,4 & 9,3 \\
\hline 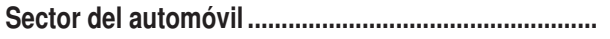 & $1.595,9$ & 5,2 & 3,5 & $-7,1$ & $5.277,3$ & 8,7 & 13,5 & 1,4 \\
\hline Automóviles y motos & 780,0 & 2,6 & 2,4 & $-23,1$ & $3.186,5$ & 5,2 & 16,6 & 3,3 \\
\hline Componentes de automóvil.......................................... & 815,9 & 2,7 & 6,3 & 16,1 & $2.090,8$ & 3,4 & 10,5 & $-1,3$ \\
\hline Bienes de consumo duradero ..................................... & 490,2 & 1,6 & 10,9 & 11,7 & $1.843,3$ & 3,0 & 22,9 & 7,1 \\
\hline 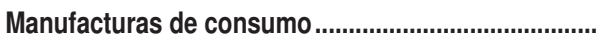 & $3.202,4$ & 10,5 & 11,4 & 17,5 & $9.066,9$ & 14,9 & 24,8 & 5,4 \\
\hline 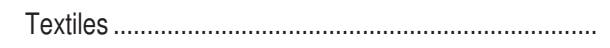 & $1.526,9$ & 5,0 & 9,0 & 20,6 & $4.683,2$ & 7,7 & 22,0 & 9,6 \\
\hline 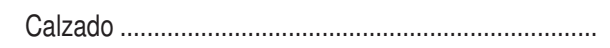 & 116,5 & 0,4 & 4,1 & 33,2 & 568,9 & 0,9 & 18,2 & 6,1 \\
\hline 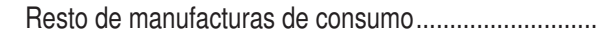 & $1.559,0$ & 5,1 & 18,5 & 13,7 & $3.814,7$ & 6,3 & 31,2 & 0,6 \\
\hline Otras mercancías & $1.136,2$ & 3,7 & 32,4 & $-8,2$ & 887,7 & 1,5 & 81,1 & $-2,5$ \\
\hline
\end{tabular}


4.15. MURCIA, REGIÓN DE. COMERCIO EXTERIOR EN 2017

(Millones de euros)

\begin{tabular}{|c|c|c|c|c|c|c|c|c|}
\hline \multirow[b]{2}{*}{ Sectores } & \multicolumn{4}{|c|}{ Exportaciones } & \multicolumn{4}{|c|}{ Importaciones } \\
\hline & Valor & $\begin{array}{l}\% \text { de } \\
\text { la CA }\end{array}$ & $\begin{array}{l}\% \text { de } \\
\text { España }\end{array}$ & $\begin{array}{c}\text { Crecim. } \\
17 / 16\end{array}$ & Valor & $\begin{array}{l}\% \text { de } \\
\text { la CA }\end{array}$ & $\begin{array}{l}\% \text { de } \\
\text { España }\end{array}$ & $\begin{array}{c}\text { Crecim. } \\
17 / 16\end{array}$ \\
\hline TOTAL GENERAL & $10.456,7$ & 100,0 & 3,8 & 16,0 & $9.667,6$ & 100,0 & 3,2 & 21,5 \\
\hline Alimentación, bebidas y tabaco & $4.719,3$ & 45,1 & 10,3 & 1,7 & $1.528,7$ & 15,8 & 4,4 & $-1,2$ \\
\hline 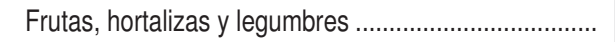 & $3.133,7$ & 30,0 & 18,2 & 0,1 & 278,5 & 2,9 & 5,2 & $-15,4$ \\
\hline 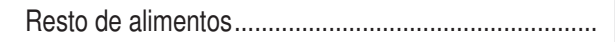 & $1.585,6$ & 15,2 & 5,6 & 5,0 & $1.250,2$ & 12,9 & 4,3 & 2,6 \\
\hline 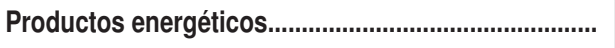 & $2.945,7$ & 28,2 & 15,0 & 58,4 & $5.637,5$ & 58,3 & 14,0 & 37,2 \\
\hline 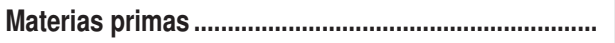 & 120,2 & 1,1 & 1,7 & 2,1 & 105,2 & 1,1 & 1,0 & 17,6 \\
\hline 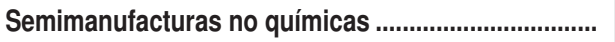 & 164,8 & 1,6 & 0,6 & 5,7 & 330,3 & 3,4 & 1,5 & 8,9 \\
\hline Hierro y acero & 104,6 & 1,0 & 1,3 & 13,5 & 155,3 & 1,6 & 1,9 & 12,7 \\
\hline Resto de semimanufacturas no químicas ....................... & 60,2 & 0,6 & 0,3 & $-5,6$ & 175,0 & 1,8 & 1,3 & 5,7 \\
\hline Productos químicos & $1.333,1$ & 12,7 & 3,4 & 14,2 & 785,3 & 8,1 & 1,7 & $-1,4$ \\
\hline 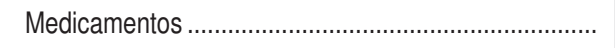 & 59,4 & 0,6 & 0,6 & $-6,3$ & 33,3 & 0,3 & 0,3 & 6,3 \\
\hline 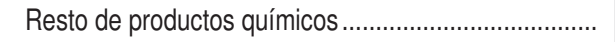 & $1.273,7$ & 12,2 & 4,5 & 15,4 & 752,0 & 7,8 & 2,4 & $-1,7$ \\
\hline Bienes de equipo & 701,1 & 6,7 & 1,2 & 7,0 & 637,0 & 6,6 & 1,0 & 41,4 \\
\hline Maquinaria para la industria & 227,0 & 2,2 & 1,6 & 14,3 & 173,5 & 1,8 & 1,0 & 20,2 \\
\hline 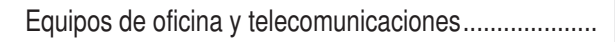 & 7,4 & 0,1 & 0,2 & 43,6 & 71,4 & 0,7 & 0,6 & 27,6 \\
\hline 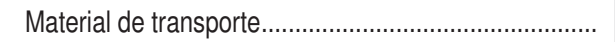 & 5,9 & 0,1 & 0,0 & $-17,1$ & 209,3 & 2,2 & 2,2 & 147,4 \\
\hline Resto de bienes de equipo & 460,7 & 4,4 & 1,9 & 3,7 & 182,8 & 1,9 & 0,7 & 10,4 \\
\hline 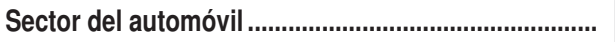 & 42,8 & 0,4 & 0,1 & 55,2 & 115,9 & 1,2 & 0,3 & $-2,4$ \\
\hline Automóviles y motos & 13,9 & 0,1 & 0,0 & $-15,6$ & 27,2 & 0,3 & 0,1 & 12,1 \\
\hline 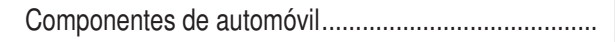 & 28,9 & 0,3 & 0,2 & 160,2 & 88,7 & 0,9 & 0,4 & $-6,2$ \\
\hline 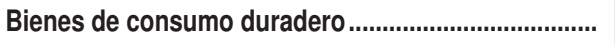 & 91,8 & 0,9 & 2,0 & $-3,6$ & 100,1 & 1,0 & 1,2 & 3,7 \\
\hline Manufacturas de consumo & 325,0 & 3,1 & 1,2 & 14,3 & 426,9 & 4,4 & 1,2 & 1,1 \\
\hline 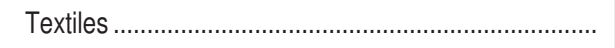 & 68,5 & 0,7 & 0,4 & 4,3 & 219,8 & 2,3 & 1,0 & 1,0 \\
\hline 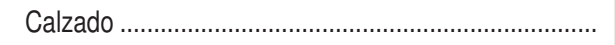 & 110,2 & 1,1 & 3,9 & 0,5 & 56,8 & 0,6 & 1,8 & 2,2 \\
\hline Resto de manufacturas de consumo & 146,3 & 1,4 & 1,7 & 34,4 & 150,3 & 1,6 & 1,2 & 0,8 \\
\hline Otras mercancías & 13,0 & 0,1 & 0,4 & 8,7 & 0,7 & 0,0 & 0,1 & $-96,9$ \\
\hline
\end{tabular}


4.16. NAVARRA, COMUNIDAD FORAL DE. COMERCIO EXTERIOR EN 2017 (Millones de euros)

\begin{tabular}{|c|c|c|c|c|c|c|c|c|}
\hline \multirow[b]{2}{*}{ Sectores } & \multicolumn{4}{|c|}{ Exportaciones } & \multicolumn{4}{|c|}{ Importaciones } \\
\hline & Valor & $\begin{array}{l}\% \text { de } \\
\text { la CA }\end{array}$ & $\begin{array}{c}\% \text { de } \\
\text { España }\end{array}$ & $\begin{array}{c}\text { Crecim. } \\
17 / 16\end{array}$ & Valor & $\begin{array}{l}\% \text { de } \\
\text { la CA }\end{array}$ & $\begin{array}{c}\% \text { de } \\
\text { España }\end{array}$ & $\begin{array}{c}\text { Crecim. } \\
17 / 16\end{array}$ \\
\hline TOTAL GENERAL ................................................................. & $8.073,7$ & 100,0 & 2,9 & $-3,2$ & $4.432,8$ & 100,0 & 1,5 & $-2,1$ \\
\hline Alimentación, bebidas y tabaco................................... & $1.148,0$ & 14,2 & 2,5 & 14,5 & 621,3 & 14,0 & 1,8 & 9,7 \\
\hline 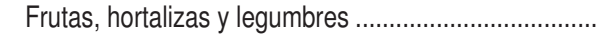 & 487,8 & 6,0 & 2,8 & 2,7 & 229,0 & 5,2 & 4,3 & 4,3 \\
\hline 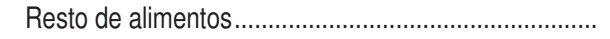 & 660,3 & 8,2 & 2,3 & 25,1 & 392,3 & 8,8 & 1,3 & 13,1 \\
\hline 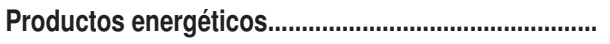 & 5,0 & 0,1 & 0,0 & 68,5 & 44,9 & 1,0 & 0,1 & $-22,1$ \\
\hline Materias primas & 193,3 & 2,4 & 2,7 & 52,0 & 211,7 & 4,8 & 2,0 & 13,9 \\
\hline Semimanufacturas no químicas ..................................... & 711,1 & 8,8 & 2,5 & 13,9 & 486,0 & 11,0 & 2,3 & 1,6 \\
\hline 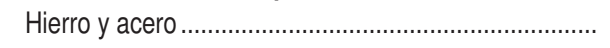 & 247,6 & 3,1 & 3,2 & 8,7 & 206,2 & 4,7 & 2,5 & 15,6 \\
\hline Resto de semimanufacturas no químicas .................... & 463,4 & 5,7 & 2,3 & 16,9 & 279,8 & 6,3 & 2,1 & $-6,7$ \\
\hline 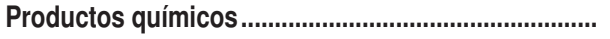 & 372,7 & 4,6 & 1,0 & 13,4 & 417,8 & 9,4 & 0,9 & $-3,3$ \\
\hline 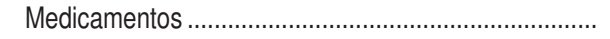 & 26,5 & 0,3 & 0,2 & 15,2 & 22,4 & 0,5 & 0,2 & $-24,4$ \\
\hline Resto de productos químicos & 346,2 & 4,3 & 1,2 & 13,2 & 395,4 & 8,9 & 1,2 & $-1,7$ \\
\hline 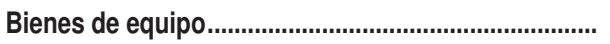 & $2.199,9$ & 27,2 & 3,9 & $-5,1$ & $1.011,8$ & 22,8 & 1,6 & 8,5 \\
\hline 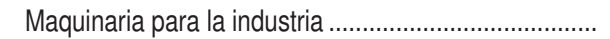 & 680,0 & 8,4 & 4,8 & 5,1 & 453,8 & 10,2 & 2,7 & 5,9 \\
\hline Equipos de oficina y telecomunicaciones..................... & 21,3 & 0,3 & 0,7 & 32,2 & 22,5 & 0,5 & 0,2 & 4,2 \\
\hline 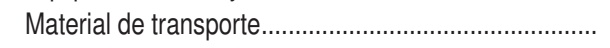 & 67,9 & 0,8 & 0,4 & $-5,5$ & 32,2 & 0,7 & 0,3 & 10,4 \\
\hline Resto de bienes de equipo & $1.430,7$ & 17,7 & 6,0 & $-9,6$ & 503,3 & 11,4 & 1,9 & 11,0 \\
\hline 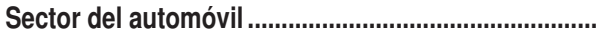 & $3.207,6$ & 39,7 & 7,1 & $-13,7$ & $1.303,7$ & 29,4 & 3,3 & $-13,6$ \\
\hline Automóviles y motos & $2.053,1$ & 25,4 & 6,4 & $-18,8$ & 44,3 & 1,0 & 0,2 & 66,5 \\
\hline Componentes de automóvil.......................................... & $1.154,5$ & 14,3 & 8,9 & $-2,7$ & $1.259,4$ & 28,4 & 6,3 & $-15,1$ \\
\hline Bienes de consumo duradero ....................................... & 117,9 & 1,5 & 2,6 & 27,7 & 89,8 & 2,0 & 1,1 & $-23,8$ \\
\hline 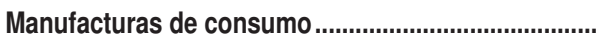 & 117,9 & 1,5 & 0,4 & $-5,5$ & 245,3 & 5,5 & 0,7 & $-0,3$ \\
\hline 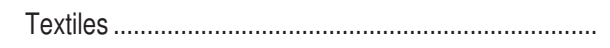 & 27,9 & 0,3 & 0,2 & 18,9 & 159,9 & 3,6 & 0,8 & $-0,9$ \\
\hline 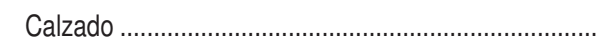 & 6,9 & 0,1 & 0,2 & 42,9 & 25,4 & 0,6 & 0,8 & 11,0 \\
\hline Resto de manufacturas de consumo .............................. & 83,1 & 1,0 & 1,0 & $-13,9$ & 60,0 & 1,4 & 0,5 & $-2,9$ \\
\hline Otras mercancías & 0,4 & 0,0 & 0,0 & $-75,1$ & 0,6 & 0,0 & 0,1 & 37,5 \\
\hline
\end{tabular}


4.17. PAÍS VASCO. COMERCIO EXTERIOR EN 2017

(Millones de euros)

\begin{tabular}{|c|c|c|c|c|c|c|c|c|}
\hline \multirow[b]{2}{*}{ Sectores } & \multicolumn{4}{|c|}{ Exportaciones } & \multicolumn{4}{|c|}{ Importaciones } \\
\hline & Valor & $\begin{array}{l}\% \text { de } \\
\text { la CA }\end{array}$ & $\begin{array}{l}\% \text { de } \\
\text { España }\end{array}$ & $\begin{array}{c}\text { Crecim. } \\
17 / 16\end{array}$ & Valor & $\begin{array}{l}\% \text { de } \\
\text { la CA }\end{array}$ & $\begin{array}{l}\% \text { de } \\
\text { España }\end{array}$ & $\begin{array}{c}\text { Crecim. } \\
17 / 16\end{array}$ \\
\hline TOTAL GENERAL & $23.860,4$ & 100,0 & 8,6 & 10,5 & $18.640,8$ & 100,0 & 6,2 & 20,6 \\
\hline Alimentación, bebidas y tabaco & 938,5 & 3,9 & 2,1 & 2,9 & $1.096,3$ & 5,9 & 3,2 & 10,7 \\
\hline 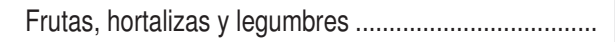 & 38,6 & 0,2 & 0,2 & $-8,0$ & 83,4 & 0,4 & 1,6 & $-5,6$ \\
\hline 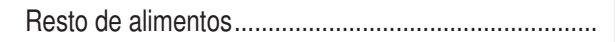 & 899,9 & 3,8 & 3,2 & 3,4 & $1.012,8$ & 5,4 & 3,5 & 12,3 \\
\hline 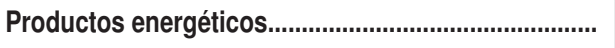 & $2.235,6$ & 9,4 & 11,4 & 32,0 & $5.020,2$ & 26,9 & 12,4 & 54,5 \\
\hline 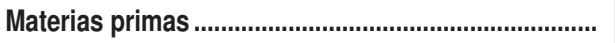 & 286,0 & 1,2 & 4,0 & 7,6 & $1.062,5$ & 5,7 & 9,9 & 18,8 \\
\hline 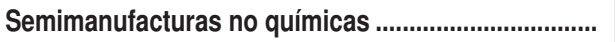 & $5.218,3$ & 21,9 & 18,6 & 9,3 & $3.217,8$ & 17,3 & 15,0 & 18,6 \\
\hline Hierro y acero & $2.311,2$ & 9,7 & 29,7 & 9,5 & $1.672,4$ & 9,0 & 20,6 & 21,3 \\
\hline Resto de semimanufacturas no químicas ....................... & $2.907,1$ & 12,2 & 14,3 & 9,2 & $1.545,4$ & 8,3 & 11,5 & 15,9 \\
\hline Productos químicos & 910,5 & 3,8 & 2,3 & $-3,3$ & $1.642,3$ & 8,8 & 3,7 & 12,1 \\
\hline 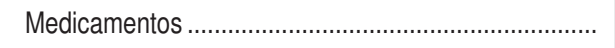 & 52,4 & 0,2 & 0,5 & $-3,5$ & 48,8 & 0,3 & 0,4 & $-15,2$ \\
\hline 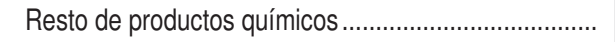 & 858,1 & 3,6 & 3,0 & $-3,3$ & $1.593,5$ & 8,5 & 5,0 & 13,2 \\
\hline Bienes de equipo & $8.676,2$ & 36,4 & 15,4 & 11,0 & $3.947,2$ & 21,2 & 6,1 & 6,5 \\
\hline Maquinaria para la industria & $2.897,3$ & 12,1 & 20,3 & 0,6 & $1.373,1$ & 7,4 & 8,2 & 3,7 \\
\hline 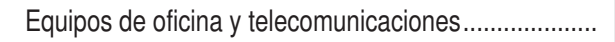 & 93,8 & 0,4 & 3,0 & 2,4 & 206,5 & 1,1 & 1,7 & $-1,3$ \\
\hline Material de transporte. & $2.247,7$ & 9,4 & 14,9 & 18,6 & 254,1 & 1,4 & 2,6 & 13,4 \\
\hline Resto de bienes de equipo & $3.437,3$ & 14,4 & 14,4 & 16,5 & $2.113,5$ & 11,3 & 8,1 & 8,5 \\
\hline 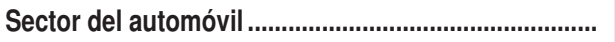 & $4.798,0$ & 20,1 & 10,6 & 9,2 & $1.621,8$ & 8,7 & 4,1 & 9,4 \\
\hline 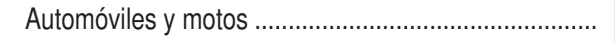 & $2.645,0$ & 11,1 & 8,2 & 11,4 & 306,4 & 1,6 & 1,6 & 12,8 \\
\hline 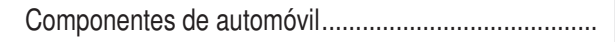 & $2.153,1$ & 9,0 & 16,6 & 6,6 & $1.315,4$ & 7,1 & 6,6 & 8,6 \\
\hline 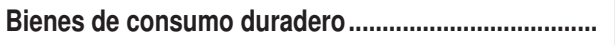 & 229,0 & 1,0 & 5,1 & 1,7 & 256,7 & 1,4 & 3,2 & $-1,2$ \\
\hline Manufacturas de consumo & 515,1 & 2,2 & 1,8 & 12,1 & 773,4 & 4,1 & 2,1 & 10,6 \\
\hline 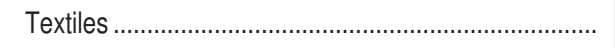 & 132,9 & 0,6 & 0,8 & 21,5 & 335,4 & 1,8 & 1,6 & 12,7 \\
\hline 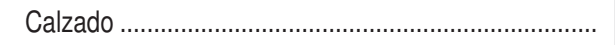 & 10,4 & 0,0 & 0,4 & 10,9 & 47,4 & 0,3 & 1,5 & 6,9 \\
\hline Resto de manufacturas de consumo & 371,8 & 1,6 & 4,4 & 9,2 & 390,7 & 2,1 & 3,2 & 9,3 \\
\hline Otras mercancías & 53,1 & 0,2 & 1,5 & $-51,5$ & 2,7 & 0,0 & 0,2 & $-30,2$ \\
\hline
\end{tabular}


4.18. RIOJA, LA. COMERCIO EXTERIOR EN 2017

(Millones de euros)

\begin{tabular}{|c|c|c|c|c|c|c|c|c|}
\hline \multirow[b]{2}{*}{ Sectores } & \multicolumn{4}{|c|}{ Exportaciones } & \multicolumn{4}{|c|}{ Importaciones } \\
\hline & Valor & $\begin{array}{l}\% \text { de } \\
\text { la CA }\end{array}$ & $\begin{array}{l}\% \text { de } \\
\text { España }\end{array}$ & $\begin{array}{c}\text { Crecim. } \\
17 / 16\end{array}$ & Valor & $\begin{array}{l}\% \text { de } \\
\text { la CA }\end{array}$ & $\begin{array}{l}\% \text { de } \\
\text { España }\end{array}$ & $\begin{array}{c}\text { Crecim. } \\
17 / 16\end{array}$ \\
\hline TOTAL GENERAL & $1.848,2$ & 100,0 & 0,7 & 8,4 & $1.361,2$ & 100,0 & 0,5 & 8,7 \\
\hline Alimentación, bebidas y tabaco & 590,6 & 32,0 & 1,3 & $-1,3$ & 349,1 & 25,6 & 1,0 & 4,0 \\
\hline 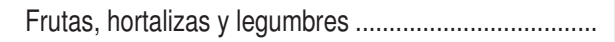 & 115,8 & 6,3 & 0,7 & 3,5 & 116,7 & 8,6 & 2,2 & 0,3 \\
\hline 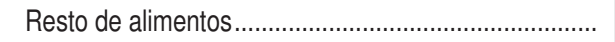 & 474,8 & 25,7 & 1,7 & $-2,4$ & 232,4 & 17,1 & 0,8 & 6,0 \\
\hline 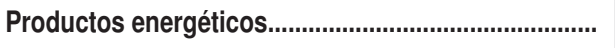 & 5,6 & 0,3 & 0,0 & 14,0 & 5,5 & 0,4 & 0,0 & 17,4 \\
\hline 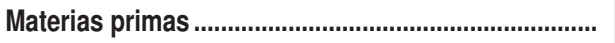 & 11,0 & 0,6 & 0,2 & 24,4 & 51,7 & 3,8 & 0,5 & 12,5 \\
\hline 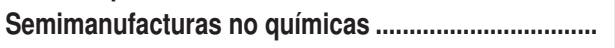 & 364,7 & 19,7 & 1,3 & 14,0 & 211,0 & 15,5 & 1,0 & 7,1 \\
\hline Hierro y acero & 24,1 & 1,3 & 0,3 & 5,4 & 35,8 & 2,6 & 0,4 & $-2,4$ \\
\hline Resto de semimanufacturas no químicas ....................... & 340,6 & 18,4 & 1,7 & 14,7 & 175,2 & 12,9 & 1,3 & 9,2 \\
\hline Productos químicos & 128,7 & 7,0 & 0,3 & 6,0 & 163,5 & 12,0 & 0,4 & 16,4 \\
\hline 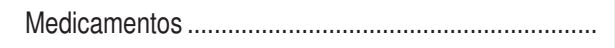 & 5,0 & 0,3 & 0,0 & $-51,2$ & 0,6 & 0,0 & 0,0 & $-15,6$ \\
\hline 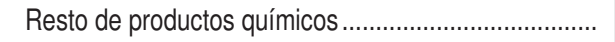 & 123,7 & 6,7 & 0,4 & 11,3 & 163,0 & 12,0 & 0,5 & 16,5 \\
\hline Bienes de equipo & 367,1 & 19,9 & 0,7 & 38,9 & 307,0 & 22,6 & 0,5 & 18,3 \\
\hline Maquinaria para la industria & 120,9 & 6,5 & 0,8 & 138,2 & 67,5 & 5,0 & 0,4 & 34,8 \\
\hline 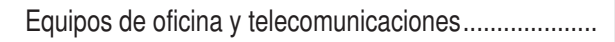 & 1,0 & 0,1 & 0,0 & 76,6 & 9,1 & 0,7 & 0,1 & 34,5 \\
\hline 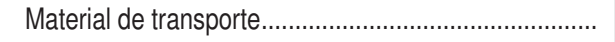 & 90,3 & 4,9 & 0,6 & 7,7 & 69,8 & 5,1 & 0,7 & 20,6 \\
\hline Resto de bienes de equipo & 154,9 & 8,4 & 0,6 & 20,0 & 160,6 & 11,8 & 0,6 & 11,0 \\
\hline 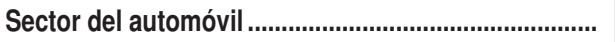 & 43,2 & 2,3 & 0,1 & $-11,8$ & 59,8 & 4,4 & 0,2 & $-12,1$ \\
\hline Automóviles y motos & 0,3 & 0,0 & 0,0 & 146,2 & 4,8 & 0,4 & 0,0 & 25,1 \\
\hline 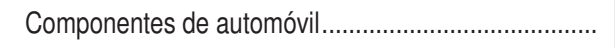 & 42,9 & 2,3 & 0,3 & $-12,1$ & 55,0 & 4,0 & 0,3 & $-14,3$ \\
\hline 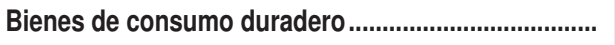 & 31,5 & 1,7 & 0,7 & 3,8 & 11,9 & 0,9 & 0,1 & $-4,4$ \\
\hline Manufacturas de consumo & 305,2 & 16,5 & 1,1 & $-0,6$ & 201,4 & 14,8 & 0,6 & 6,9 \\
\hline 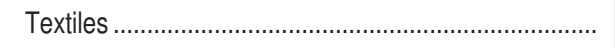 & 53,8 & 2,9 & 0,3 & 0,3 & 72,2 & 5,3 & 0,3 & 11,1 \\
\hline 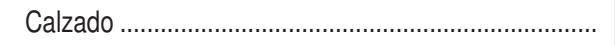 & 233,7 & 12,6 & 8,3 & 0,3 & 88,0 & 6,5 & 2,8 & 2,7 \\
\hline Resto de manufacturas de consumo & 17,6 & 1,0 & 0,2 & $-13,8$ & 41,2 & 3,0 & 0,3 & 9,4 \\
\hline Otras mercancías & 0,6 & 0,0 & 0,0 & 33,7 & 0,2 & 0,0 & 0,0 & $-0,5$ \\
\hline
\end{tabular}


4.19. EXPORTACIONES POR PROVINCIAS RANKING RESPECTO AL AÑO 2017

(Millones de euros)

\begin{tabular}{|c|c|c|c|c|c|c|}
\hline Provincias & 2012 & 2013 & 2014 & 2015 & 2016 & $2017^{*}$ \\
\hline 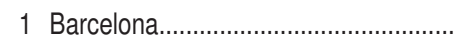 & $45.444,3$ & $45.828,8$ & $47.184,1$ & $50.166,5$ & $51.189,5$ & $54.771,6$ \\
\hline 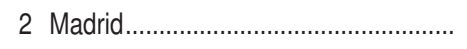 & $27.941,7$ & $30.771,4$ & $27.731,4$ & $27.775,8$ & $28.759,7$ & $30.510,3$ \\
\hline 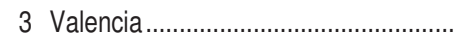 & $11.473,6$ & $13.421,9$ & $14.240,7$ & $16.965,0$ & $17.181,2$ & $17.381,7$ \\
\hline 4 Coruña, A & $8.018,3$ & $8.495,5$ & $7.682,2$ & $8.291,1$ & $9.403,8$ & $11.009,6$ \\
\hline 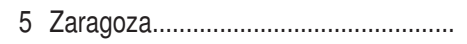 & $7.705,0$ & $7.667,5$ & $8.283,2$ & $9.267,6$ & $9.728,2$ & $10.717,5$ \\
\hline 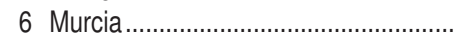 & $8.956,2$ & $9.353,0$ & $10.440,7$ & $9.379,2$ & $9.026,2$ & $10.456,7$ \\
\hline 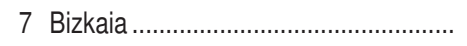 & $8.491,1$ & $8.721,1$ & $9.832,8$ & $9.053,1$ & $8.089,6$ & $9.545,4$ \\
\hline 8 Pontevedra & $7.010,1$ & $8.434,1$ & $8.334,5$ & $8.670,9$ & $9.111,7$ & $9.171,5$ \\
\hline 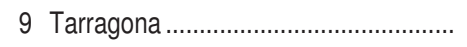 & $7.545,5$ & $7.122,2$ & $7.061,8$ & $7.209,7$ & $7.269,3$ & $8.679,6$ \\
\hline 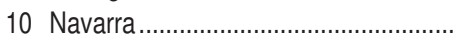 & $7.235,8$ & $7.447,2$ & $8.141,1$ & $8.539,7$ & $8.437,2$ & $8.073,7$ \\
\hline 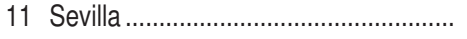 & $3.995,6$ & $4.585,8$ & $5.014,7$ & $5.265,3$ & $6.940,7$ & $7.589,8$ \\
\hline 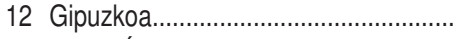 & $7.069,1$ & $6.608,2$ & $7.007,1$ & $6.987,7$ & $6.812,9$ & $7.179,0$ \\
\hline 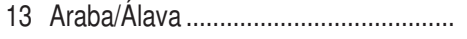 & $5.410,6$ & $5.302,0$ & $5.661,2$ & $5.824,8$ & $6.713,0$ & $7.136,0$ \\
\hline 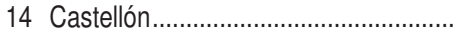 & $5.356,2$ & $5.656,1$ & $5.908,9$ & $6.286,3$ & $6.478,8$ & $6.864,1$ \\
\hline 15 Huelva................ & $6.062,9$ & $5.685,7$ & $5.877,6$ & $4.607,7$ & $4.408,4$ & $6.384,1$ \\
\hline 16 Cádiz.............. & $8.178,4$ & $8.315,2$ & $7.510,0$ & $6.075,8$ & $5.658,8$ & $6.214,9$ \\
\hline 17 Valladolid..... & $3.592,1$ & $4.619,1$ & $5.449,0$ & $5.508,8$ & $5.761,8$ & $5.797,6$ \\
\hline 18 Girona & $4.244,7$ & $4.272,7$ & $4.344,7$ & $4.639,6$ & $4.728,9$ & $5.301,2$ \\
\hline 19 Alicante & $4.111,4$ & $4.530,9$ & $4.851,4$ & $4.968,4$ & $5.005,5$ & $5.125,2$ \\
\hline 20 Asturias & $3.837,5$ & $3.843,6$ & $3.838,4$ & $3.791,0$ & $3.510,7$ & $4.175,6$ \\
\hline 21 Almería & $2.439,3$ & $2.702,6$ & $2.726,6$ & $3.125,8$ & $3.378,2$ & $3.617,3$ \\
\hline 22 Palencia & $1.978,7$ & $1.636,7$ & $1.406,8$ & $2.311,3$ & $3.819,0$ & $3.472,8$ \\
\hline 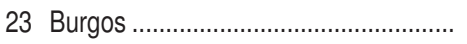 & $3.146,5$ & $3.138,5$ & $3.009,9$ & $3.604,7$ & $3.519,8$ & $3.107,8$ \\
\hline 24 Córdoba & $1.651,5$ & $1.799,6$ & $1.982,9$ & $2.072,5$ & $2.178,6$ & $2.448,8$ \\
\hline 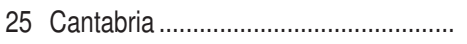 & $2.713,4$ & $2.457,5$ & $2.546,5$ & $2.342,1$ & $2.345,2$ & $2.319,2$ \\
\hline 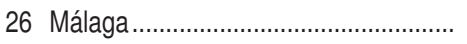 & $1.392,0$ & $1.382,3$ & $1.642,5$ & $1.806,6$ & $1.995,8$ & $2.198,2$ \\
\hline 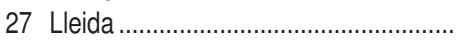 & $1.618,8$ & $1.733,5$ & $1.700,6$ & $1.869,3$ & $1.954,4$ & $2.076,3$ \\
\hline 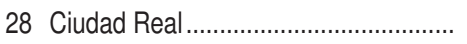 & $1.611,0$ & $1.703,2$ & $1.815,5$ & $1.809,3$ & $1.760,6$ & $2.072,6$ \\
\hline 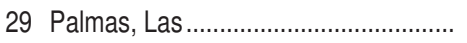 & $1.743,7$ & $1.823,9$ & $1.751,8$ & $1.994,1$ & $1.613,0$ & $1.931,9$ \\
\hline 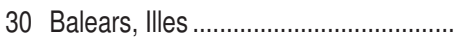 & $1.016,2$ & 834,0 & 924,0 & $1.157,2$ & $1.167,2$ & $1.853,6$ \\
\hline 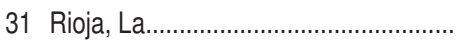 & $1.474,7$ & $1.510,8$ & $1.644,4$ & $1.700,0$ & $1.704,4$ & $1.848,2$ \\
\hline 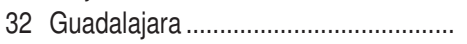 & 780,5 & 975,9 & $1.227,5$ & $1.550,6$ & $1.753,4$ & $1.808,1$ \\
\hline 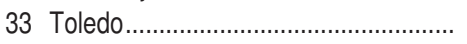 & 927,7 & $1.045,9$ & $1.257,3$ & $1.403,8$ & $1.538,1$ & $1.692,1$ \\
\hline 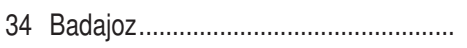 & $1.290,7$ & $1.253,4$ & $1.261,9$ & $1.306,7$ & $1.284,2$ & $1.450,2$ \\
\hline 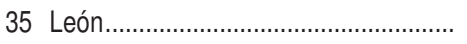 & $1.531,2$ & $1.188,4$ & $1.242,2$ & $1.498,3$ & $1.429,1$ & $1.428,5$ \\
\hline 36 Jaén & 642,4 & 729,1 & 970,1 & 946,6 & $1.178,8$ & $1.265,3$ \\
\hline 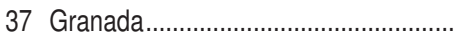 & 877,7 & 924,3 & 925,2 & $1.030,2$ & $1.083,9$ & $1.195,0$ \\
\hline 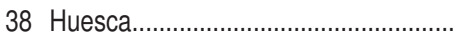 & 903,3 & 981,1 & 867,9 & 897,4 & 897,6 & 972,6 \\
\hline 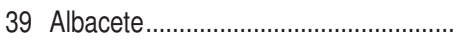 & 744,8 & 814,0 & 764,9 & 849,4 & 902,9 & 969,2 \\
\hline 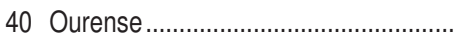 & 698,3 & 741,4 & 826,7 & 787,7 & 787,5 & 815,6 \\
\hline 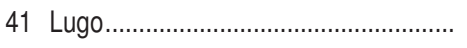 & 936,2 & $1.087,1$ & 966,3 & $1.174,4$ & 678,2 & 679,6 \\
\hline 42 Salamanca & 733,9 & 882,6 & 783,5 & 918,8 & 715,6 & 675,2 \\
\hline 43 Santa Cruz de Tenerife.......................... & 821,2 & 795,3 & 640,7 & 458,5 & 448,9 & 601,7 \\
\hline 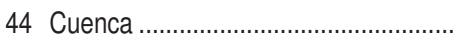 & 272,1 & 327,3 & 333,7 & 400,3 & 471,2 & 513,9 \\
\hline 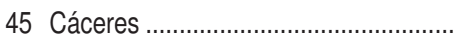 & 376,4 & 414,2 & 411,8 & 413,7 & 405,1 & 468,8 \\
\hline 46 Soria & 264,7 & 271,8 & 325,1 & 402,1 & 396,5 & 451,3 \\
\hline 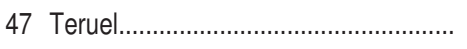 & 183,5 & 218,4 & 231,2 & 406,1 & 269,3 & 329,8 \\
\hline 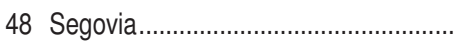 & 223,0 & 256,1 & 287,7 & 300,5 & 311,4 & 320,9 \\
\hline 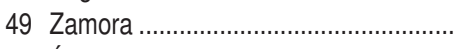 & 149,2 & 162,2 & 149,8 & 172,3 & 195,1 & 201,5 \\
\hline 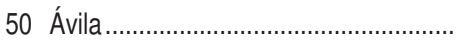 & 86,5 & 115,6 & 97,8 & 164,6 & 180,9 & 141,9 \\
\hline 51 Melilla................................................ & 77,8 & 34,2 & 30,0 & 43,0 & 48,3 & 49,7 \\
\hline 52 Ceuta & 2,8 & 3,1 & 7,9 & 6,9 & 3,1 & 20,8 \\
\hline
\end{tabular}




\subsection{MAPAS DE LOS PRINCIPALES SECTORES EXPORTADORES}

EN 2017 - POR PROVINCIA

(Millones de euros)

Automóviles y motos

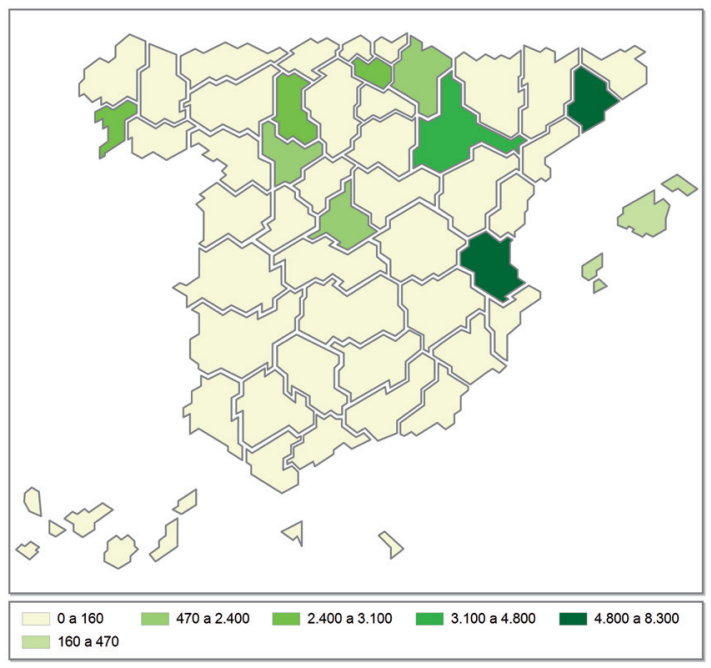

Frutas, hortalizas y legumbres

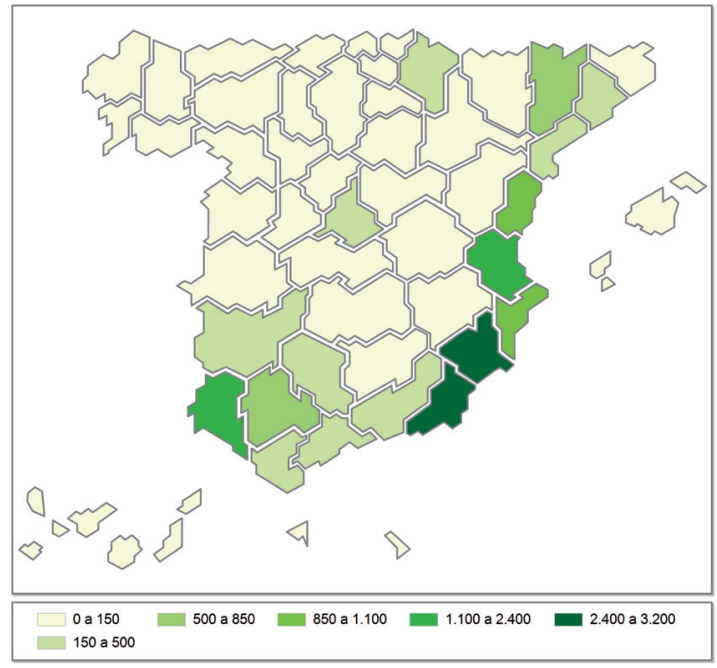

Medicamentos

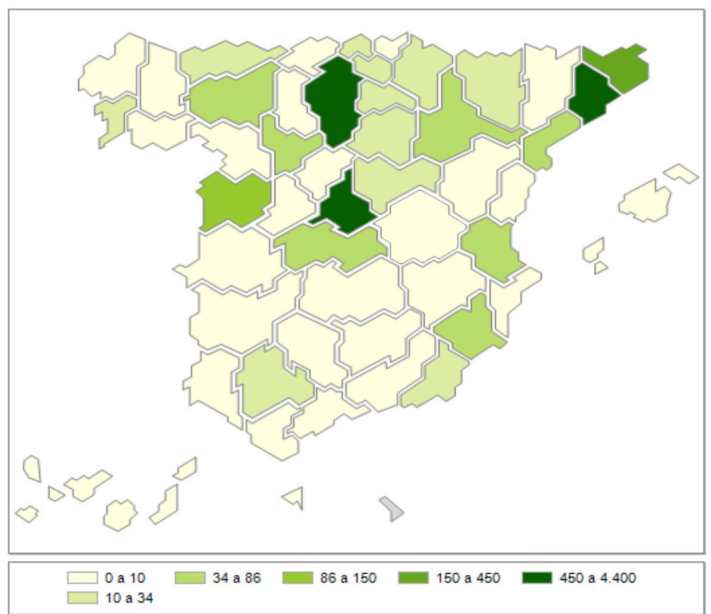

Petróleo y derivados

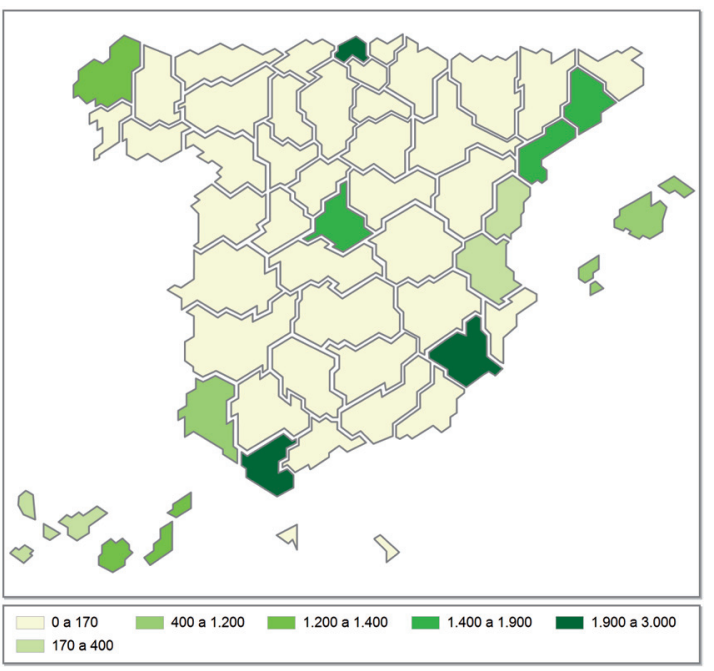

Componentes del automóvil

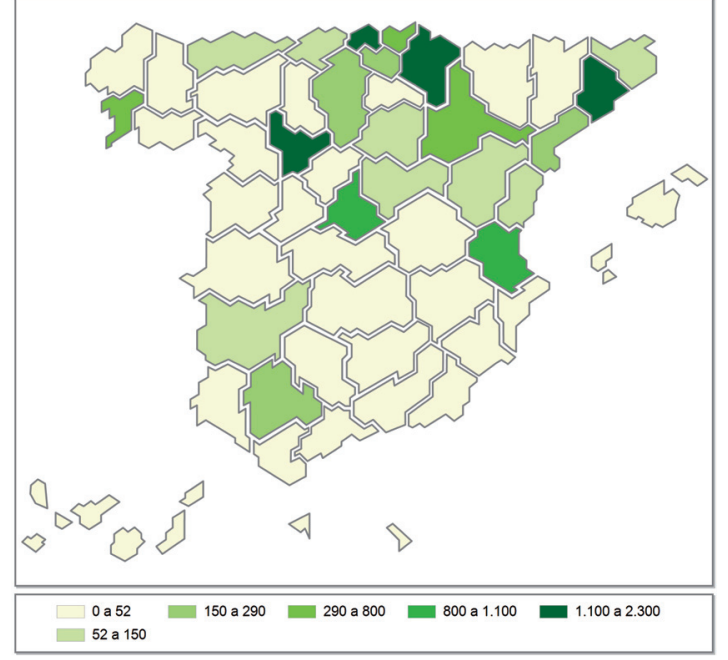

Maquinaria de uso general para la industria

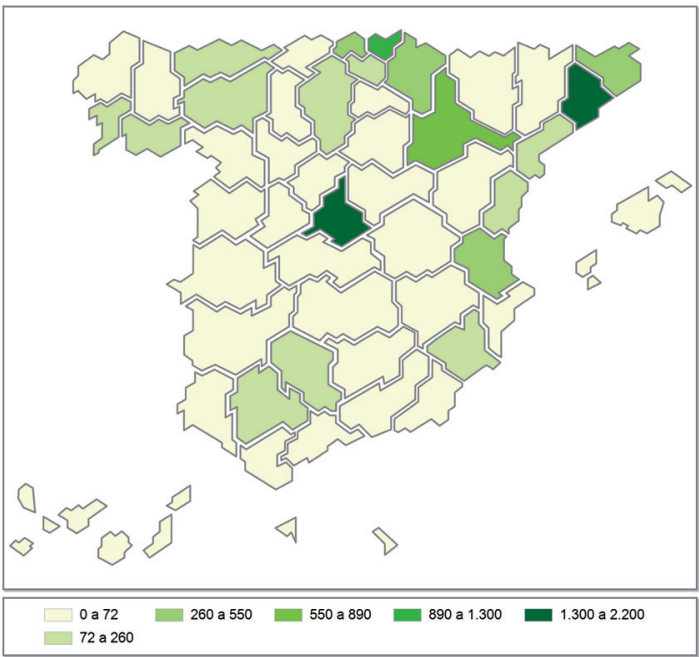


4.20. MAPAS DE LOS PRINCIPALES SECTORES EXPORTADORES

EN 2017 - POR PROVINCIA (continuación)

(Millones de euros)
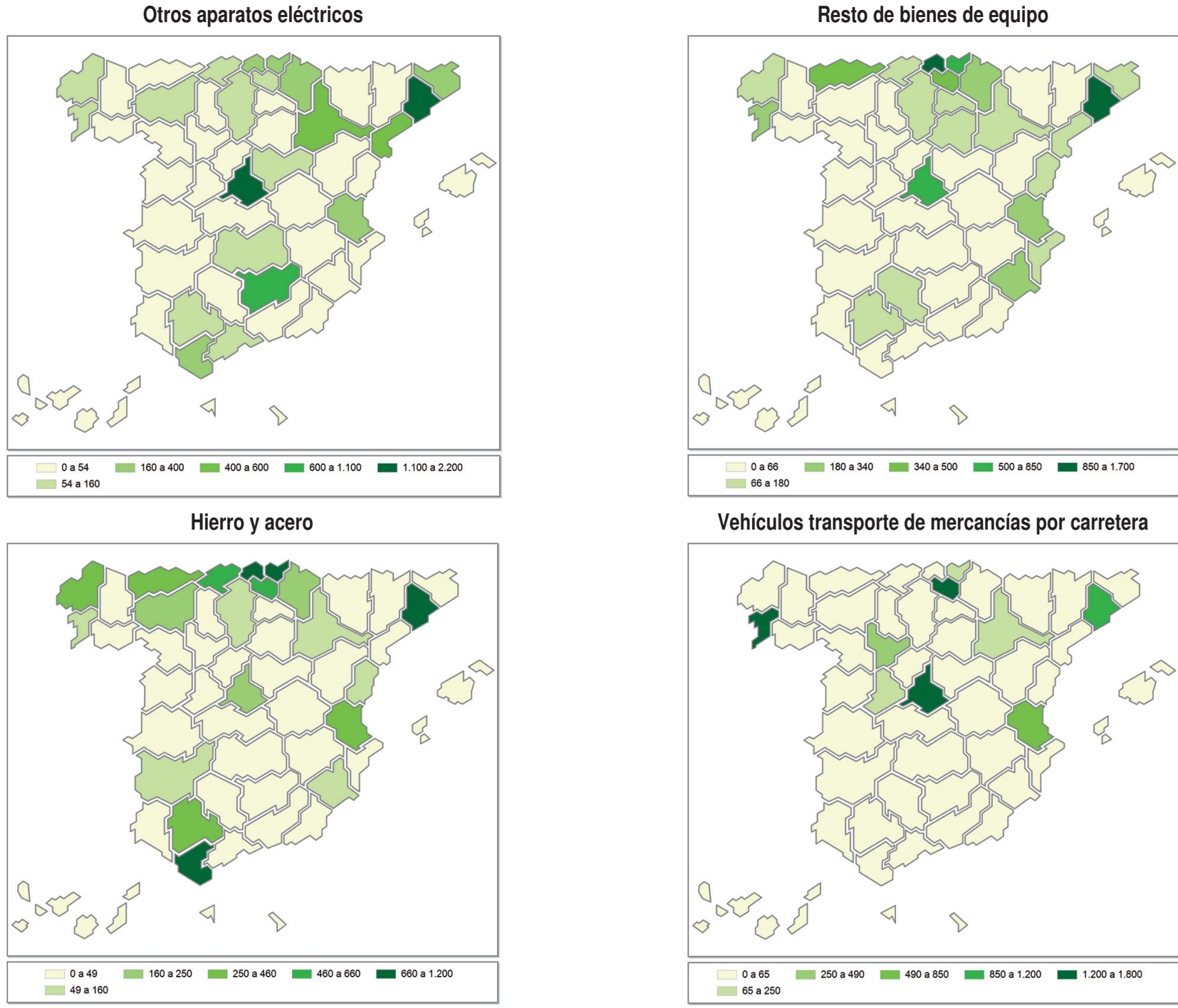

Vehículos transporte de mercancías por carretera

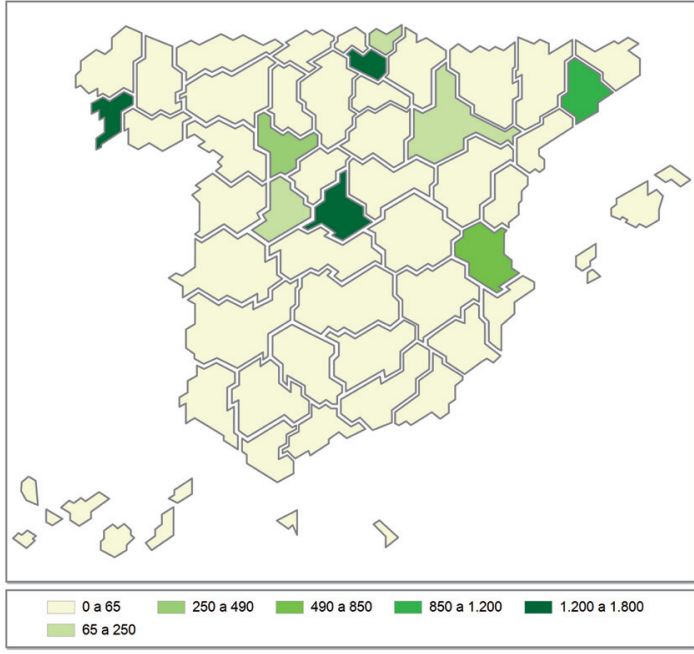

Productos cárnicos
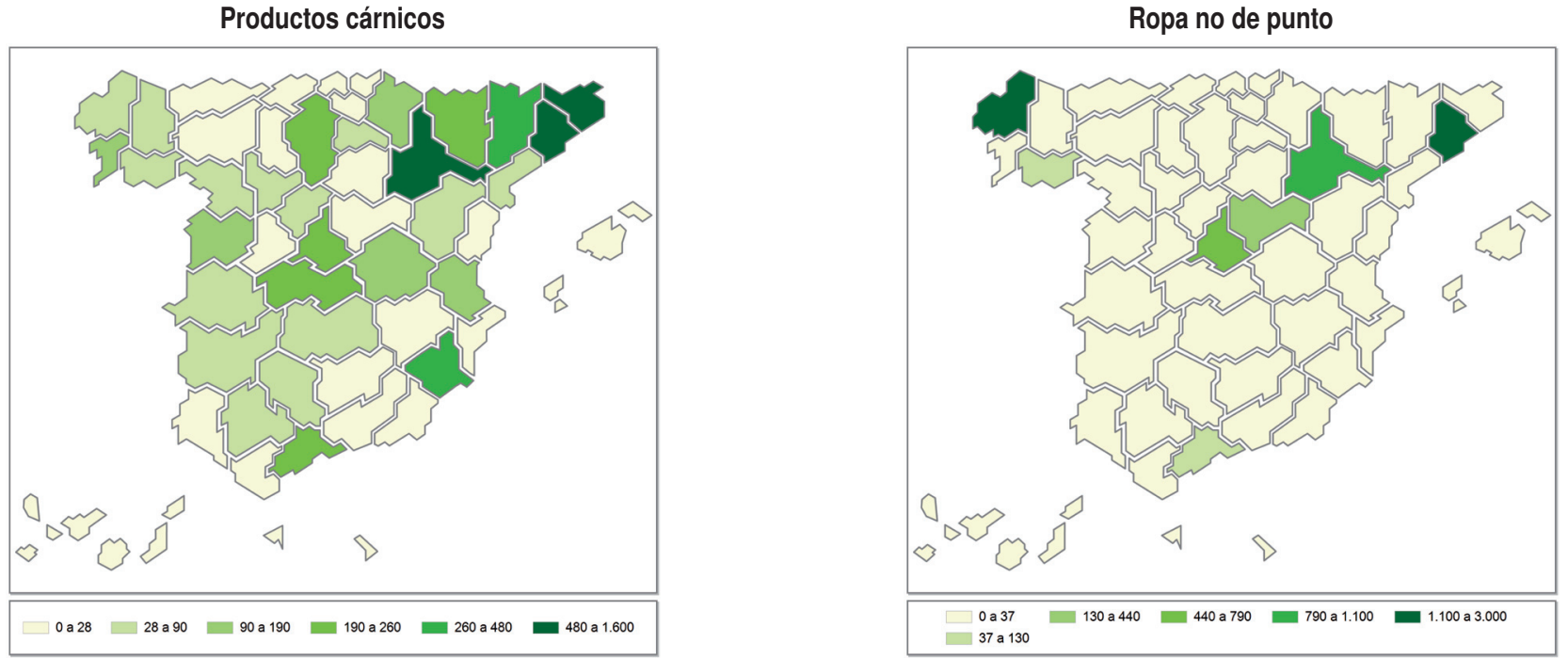

Fuente: Subdirección General de Estudios y Evaluación de Instrumentos de Política Comercial de la Secretaría de Estado de Comercio, con datos del Departamento de Aduanas e IIEE de la Agencia Tributaria. 